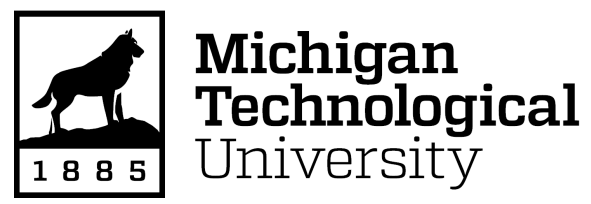

Michigan Technological University Digital Commons @ Michigan Tech

Dissertations, Master's Theses and Master's Reports

2016

USE OF LIDAR IN THE DESIGN OF GRASSED WATERWAYS: CASE STUDY IN AGRICULTURAL MANAGEMENT IN OKLAHOMA

Annette Sparks

Michigan Technological University, sparksals89@gmail.com

Copyright 2016 Annette Sparks

Recommended Citation

Sparks, Annette, "USE OF LIDAR IN THE DESIGN OF GRASSED WATERWAYS: CASE STUDY IN AGRICULTURAL MANAGEMENT IN OKLAHOMA", Open Access Master's Report, Michigan Technological University, 2016.

https://doi.org/10.37099/mtu.dc.etdr/109

Follow this and additional works at: https://digitalcommons.mtu.edu/etdr

Part of the Biological Engineering Commons, Bioresource and Agricultural Engineering Commons, and the Environmental Engineering Commons 


\title{
USE OF LIDAR IN THE DESIGN OF GRASSED WATERWAYS: \\ CASE STUDY IN AGRICULTURAL MANAGEMENT IN OKLAHOMA
}

By

Annette L. Sparks

\begin{abstract}
A REPORT
Submitted in partial fulfillment of the requirements for the Degree of MASTER OF SCIENCE

In Environmental Engineering
\end{abstract}

\section{MICHIGAN TECHNOLOGICAL UNIVERSITY}

2016

(C) 2016 Annette L. Sparks 
This report has been approved in partial fulfillment of the requirements for the Degree of MASTER OF SCIENCE in Environmental Engineering.

Department of Civil and Environmental Engineering

\author{
Report Advisor: $\quad$ David W. Watkins \\ Committee Member: $\quad$ Martin T. Auer \\ Committee Member: Ann L. Maclean \\ Department Chair: $\quad$ David W. Hand
}


TABLE OF CONTENTS

ACKNOWLEDGEMENTS .............................................................................................. IV

ABSTRACT ........................................................................................................................... V

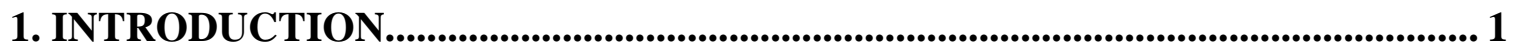

1.1 OVERVIEW \& OBJECTIVES .................................................................................. 1

1.2 HISTORY OF THE NRCS AND CONSERVATION MANAGEMENT IN OKLAHOMA ..... 2

1.3 LiDAR TECHNOLOGY AND APPLICATIONS TO WATERSHED MANAGEMENT........ 5

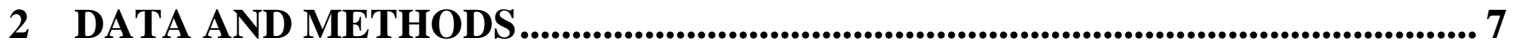

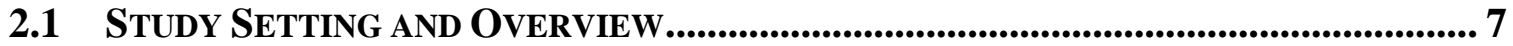

2.2 Fundamental Calculations..................................................10

2.3 ENGINEERING FIELD TOOL EQUATIONS ....................................................... 12

2.4 NRCS WATERSHED TOOL ..................................................................................... 13

$3 \quad$ RESULTS \& DISCUSSION ........................................................................................ 14

4 CONCLUSION ........................................................................................................... 20

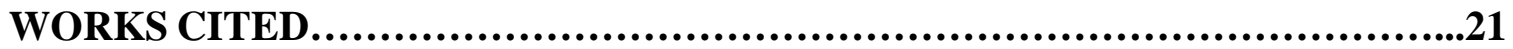

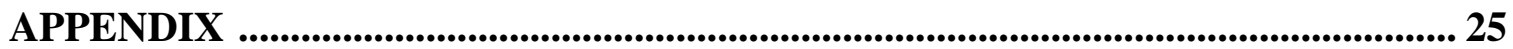




\section{Acknowledgements}

For 16 weeks I had the opportunity to work as an engineering intern for the Natural Resources Conservation Service (NRCS) and learned firsthand the daily routine of serving the farmers through the design, installation, and maintenance of sustainable agricultural practices.

I would like to thank the following individuals and institutions for the significant contributions made to this research. It would not have been possible without the time, resources, expertise, instruction, patience, referrals, recommendations, and support of everyone listed. Thank you all very much for everything:

Mr. Jamey Wood, Ms. Stacey Riley, Mr. Rusty Peterson, Ms. Melissa Thompson, Mr. Dennis Brorsen, Ms. Jolene Sparks, Mr. Wade Warren, Mr. Dan Smith \& Mrs. Smith \& family, Mr. Mike Goforth, Ms. Lisa Sauer, Mr. Troy Collier, Ms. Andrea Lane, and Ryan McCloud of the Natural Resources Conservation Service (NRCS) Oklahoma; Farm Service Agency Oklahoma; Mr. Greg Hadish, NRCS lowa; Mr. Kent Pena, NRCS Wisconsin; Mr. Chris Morse, NRCS Indiana; Mr. Joel Nelson, United States Department of Agriculture; Dr. David W. Watkins, Dr. Martin T. Auer, Dr. Ann L. Maclean, Dr. Kari B Henquinet, Dr. Blair Orr, and Dr. Michael J. Falkowski, Michigan Technological University; Dr. G. Allen Finchum, Oklahoma State University; Dr. Abolghasem Shahbazi, Dr. Godfrey A. Gayle, Dr. Manuel R. Reyes, and Dr. Lijun Wang, Biological Engineering Program at North Carolina A\&T State University; and Ms. Kori Lelaka.

Prior to this study, permission was obtained from the Oklahoma NRCS state office to access design notes for grassed waterways designed using the topographic method, kept in the Perry Field Service Center, and to conduct this research in addition to primary training and duties. Mr. Peterson, Mr. Brorsen, Ms. Thompson, Ms. Sparks, Mr. Smith, and Mr. Goforth each helped with the access and understanding of design notes.

Ms. Sauer, Mr. Peterson, Mr. Hadish, and Mr. Pena assisted with the creation of the ArcGIS workspace similar to that in the office on a personal laptop for continuation of the research beyond the 16-week internship. Mr. Pena and Dr. Maclean assisted with the troubleshooting of the GIS software. 


\begin{abstract}
Before the advent of Light Detection and Ranging (LiDAR) technology, farm-level infrastructure for sustainable agriculture was designed using topographic maps. LiDAR is a remote sensing method whereby reflected laser pulses are measured to generate high-resolution 3D images of the terrain. This report compares these two methods in the design of grassed waterways for flood drainage and evaluates how the quantitative difference between the two methods can affect the overall hydrologic design. The benefits of LiDAR are expected to be higher accuracy and precision in design, as well as greater reproducibility or consistency, regardless of the designer. To carry out this analysis, design notes from 2001 to 2011 were acquired from the Perry Field Service Center of the Natural Resources Conservation Service (NRCS) of the US Department of Agriculture (USDA), and designs for thirty grassed waterways were randomly selected from Noble County, OK. ArcGIS was used to delineate the watersheds and compute the drainage areas and average watershed slopes for twenty-eight grassed waterways using LiDAR data. The NRCS Engineering Field Tool was then used to calculate the time of concentration, runoff depth, and peak discharge for the 10-year 24-hour storm, selected to match stated design criteria. These estimates were then compared to the original design notes, which were based on design methods using topographic maps. The results indicated a significant difference $(p=0.0001)$ in the mean watershed slopes, yielding lower times of concentration values and higher peak flow values with the LiDAR method. Smaller differences arise from the watershed delineation by LiDAR and the calculation of the runoff curve number (due to inclusion of more soil types). For a complete understanding of how methods based on LiDAR and topographic maps compare, this study should be done on a larger scale including different types of drainage structures. Until further study can be done, it is recommended that the topographic method be used in conjunction with the LiDAR method as a means for checking and adjusting for slope errors common to the LiDAR method.
\end{abstract}




\section{Introduction}

\subsection{Overview \& Objectives}

Topographic maps show the heights and depths of various terrains through contours-interpolated lines that join at points of equal elevation (36). Systematic topographic mapping of the United States began in 1884 (14), and topographic maps have been used to design sustainable agricultural practices since the beginning of organized land management. All federal agencies that create maps use the United States National Map Accuracy Standards, issued by the U.S. Bureau of Budget in 1941 and finalized in 1947. For horizontal accuracy, 90\% of all tested points of the USGS topographic map with a typical scale of $1: 24,000$ must be accurate to $1 / 50^{\text {th }}$ of an inch ( 0.05 centimeters), which is equivalent to 40 feet ( 12.2 meters). For vertical accuracy, $90 \%$ of all tested elevation points must be correct to half of the contour interval. For example, if a topographic map with a scale of 1:24,000 has a contour interval of 10 feet, $90 \%$ of the tested points should be within 5 feet (1.5 meters) (33). The Natural Resources Conservation Service (NRCS) New Hampshire has a document detailing the steps to delineating a watershed using topographic maps, commonly known as the New Hampshire Method (5).

Over the past 130 years, the methods used to create maps have evolved from field surveys to photogrammetry to computer-based methods (10). Today, topographic maps are used for land management, natural resource management, community development, and health and safety services by governments, private industries, nongovernmental organizations, and individuals (35). Airborne LiDAR is a relatively new remote sensing method whereby light is emitted in pulses from an aircraft using a laser and return signals are recorded by a scanner and specialized GPS, generating 3D images of the terrain (30). Although LiDAR is now widely used in the field, there has been little assessment of the quantitative differences that arise in the design of sustainable agricultural practices depending on the method used (conventional topographic maps vs. LiDAR) and the effect those differences have on overall hydrologic design for best management practices. 
The objectives of this study are to assess the quantitative differences between the two methods and evaluate how those differences potentially affect hydrologic design. As a case study, 30 randomly selected grassed waterways in Noble County, Oklahoma are analyzed. LiDAR data for Noble County arrived in the Perry Field Service Center of the NRCS in 2012, and other field offices in Oklahoma are due to receive LiDAR data in 2016. The three most commonly encountered watershed management structures in Noble County were ponds, grassed waterways, and grade stabilization structures.

\subsection{History of NRCS and Conservation Management in Oklahoma}

In the 1890s, soil erosion was recognized as a national problem through surveys conducted by the Bureau of Soils of the US Department of Agriculture (USDA). The "Father of Conservation", Hugh Hammond Bennett drew attention to the results of the surveys, stressing that soil erosion, if left unmanaged, could threaten national food security (15). The Soil Erosion Service (SES) was established in 1933 as a public works program by Congress in response to the 1930's dust storms, floods, droughts and crop failures. In 1935, the SES became the Soil Conservation Service (SCS), expanding its mission from erosion control to conservation, with Bennet as the first chief. The SCS worked with farmers directly, providing technical assistance for conservation practices (i.e., crop rotation, contour farming, and pasture management), and 5-year project agreements involving labor, seeds, and trees. In 1994, the USDA reorganized and the SCS was renamed the NRCS (15). Today, the NRCS has a presence in every state. With the motto, "Helping People Help the Land," their mission is accomplished through providing farmers access to a network of engineers, technicians, scientists, and conservationists by way of field service offices and technical service offices. In Oklahoma, each of the 77 counties has a field service office, with further sub-division into teams and zones.

Oklahoma was opened for settlement in 1889 and was the focus of many early agricultural conservation efforts. In 1920, terrace demonstrations began in Oklahoma. This was one of the earliest conservation efforts in the state, even though the primary focus was food production and not conservation. In 1929, ten soil experiment stations were constructed in the state near 
agricultural institutions. The Dust Bowl of 1935 also prompted many conservation efforts in Oklahoma and other affected Midwestern states (15).

Oklahoma was the first state to build flood control dams. The first flood control dam built in the nation was Cloud Creek Watershed Dam No.1 in Washita County, Oklahoma. Flooding was a major problem in Oklahoma in the early to mid-1900s. Seventy floods were recorded along Wildhorse Creek between 1923 and 1942. Together, Bear Creek, Fall Creek, and Coon Creek experienced 114 floods between 1933 and 1950, of which 43 floods covered 50\% or more of the flood plain. One of the worst floods of the $20^{\text {th }}$ century in the United States occurred in western Oklahoma on April 4, 1934. The Washita River overflowed its banks during the night, killing 17 people in Hammon and causing millions of dollars in damages. In 1936, the Flood Control Act was passed, and the SCS began building flood retarding dams to create smaller, more manageable watersheds (15). The dams were designed to temporarily store runoff during a storm event and slowly release the water following the event. Many of these dams are still in use today. According to the Oklahoma Conservation District, there are a total of 2,107 dams and 129 watersheds in the state. An estimated $\$ 81$ million dollars in benefits is generated annually from these structures (29).

The first dams constructed were designed with a life span of up to 50 years (15). The dams typically consist of an earth embankment 6 to $20 \mathrm{~m}$ high, a concrete pipe 0.3 to $1.8 \mathrm{~m}$ in diameter as the principal outlet, and an auxiliary spillway, as shown in Figure 1. Because dams were constructed in the uppermost regions of watersheds, the upstream drainage area is typically only 1.6 to $16 \mathrm{~km}^{2}(28)$. To reduce runoff and sedimentation and extend the life of the dams, the directives of the Flood Control Act also called for sustainable agricultural practices to be installed upstream of the dams. These practices included grass plantings, terraces, ponds, and grade stabilization structures (15).

Grassed waterways (Figure 2) are broad shallow channels sown with fast growing grass and placed in large fields in order to reduce erosion and increase infiltration. They are a common erosion and flood control practice in North American agriculture. For maintenance, the structures are mowed periodically to reduce hydraulic roughness and prevent gullying. Though grassed 
waterways have been known to reduce sediment delivery by $97 \%$ (24), according to Bennett et al. (28), more than 2,200 flood control dams nationwide will still need rehabilitation in the near future. LiDAR could be a useful tool in the design process with regards to watershed delineation and hydrologic analysis.

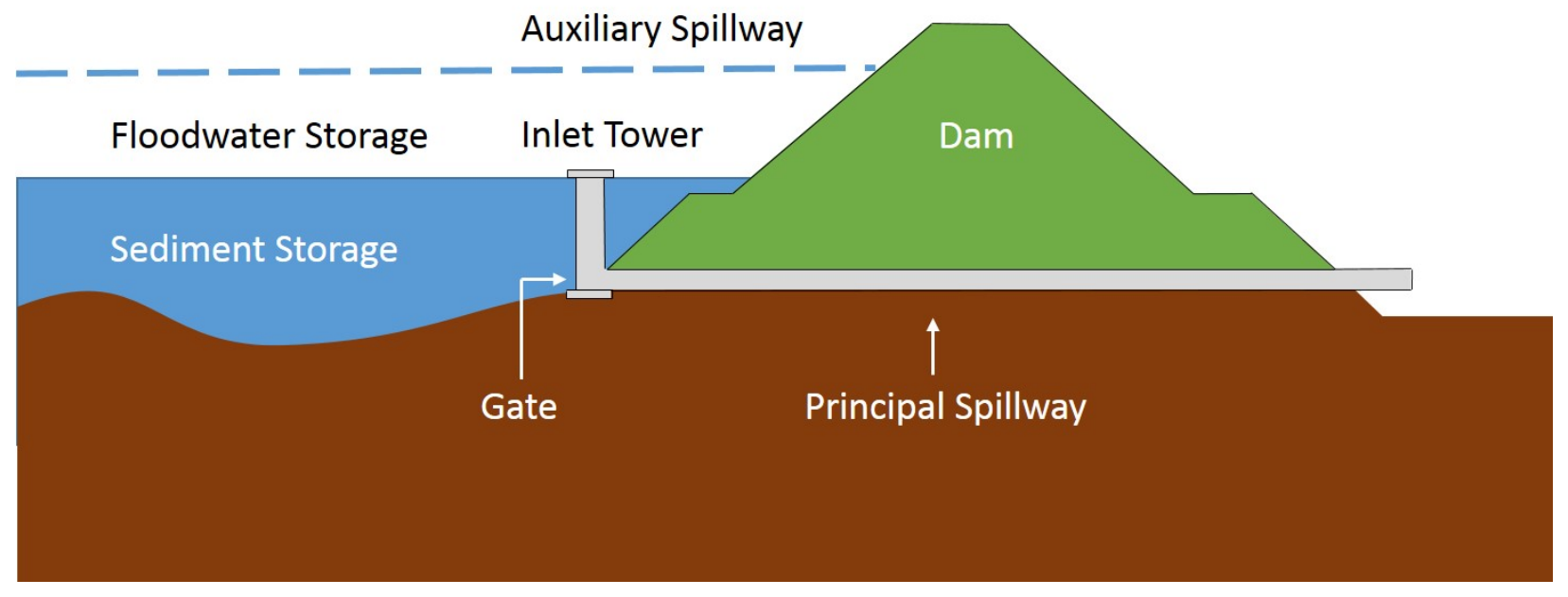

Figure 1: Cross section of a flood control dam (adapted from 23)

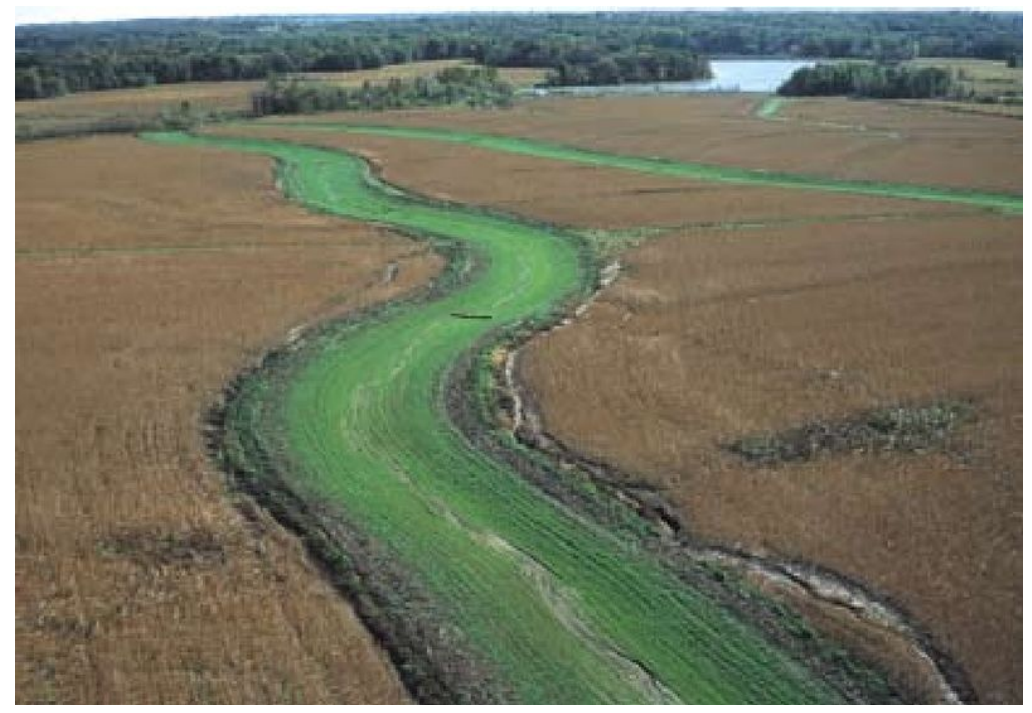

Figure 2: Grassed Waterways (4). 


\subsection{LiDAR Technology and Applications to Watershed Management}

LiDAR is a very accurate method for creating digital elevation models (DEMs), compared to conventional methods. Liu et al. (2005) were successful in generating high-resolution DEMs via LiDAR. They point out how terrain patterns (which ultimately help determine hydrologic variables) are crucial to watershed management, and their results show LiDAR does a far better job of capturing these patterns than do topographic maps, field surveys, or photogrammetry (37). Murphy et al. (2007) were also successful in generating high-resolution DEMs using LiDAR to model the stream network of a 193 ha watershed. Comparing LiDAR to photogrammetry, the stream network derived from LiDAR was more accurate (28). According to Hudak et al. (2009), the use of LiDAR technology grew immensely from 1990-2009, during which time it was used in applications ranging from forestry and wildlife to geology and surface hydrology. They noted LiDAR was used specifically to map channels and shallow water refuge habitats for the purpose of stream restoration for salmon (6).

Amatya et al. (2013) were successful in using LiDAR to delineate historical watersheds in South Carolina. The watersheds studied were once used for agricultural purposes in the 1700 s, and still contained functioning grassed waterways, even though the land was reverted back to forest in the 1800s. Significantly, they note that it is important to have an accurate estimate of the drainage area so as to have accurate hydrologic calculations (peak flow, runoff volume, and water and chemical balance), which are ultimately used to design grassed waterways. Topographic maps alone were not sufficient for their study; LiDAR data had to be utilized. They state in their conclusion, "DEMs based on high resolution topographic data such as LiDAR with field verification for cross drainage structures...should be used for estimating more reliable boundary/drainage areas often used in hydrologic studies...," illustrating the need for LiDAR data in land management and hydrologic assessment (8).

LiDAR has limitations, however, which must be considered in any study. For example, in a study by Krogstad and Schiess (2004), they point out that while LiDAR can produce high-resolution DEMs of terrains of various types, it can sometimes fail to "see" the ground (i.e. few to no ground returns), thus requiring field verification in some cases, "even with millions of laser pulses". Areas 
with few returns tend to be areas of dense vegetation, where there is poor canopy penetration with LiDAR. As a rule of thumb, they recommend that if you cannot see the sky from the ground, chances are LiDAR cannot "see" the ground (16).

LiDAR is also known to have errors in elevation which affect the calculation of the average slope of an area, with average slope calculated, for example, using a rise-over-run algorithm by the Spatial Analyst tool in GIS. Hodgsen et al. (2005) did a leaf-off study of elevation and slope data derived from LiDAR in a watershed with six different vegetation cover classes in North Carolina. A professional-grade survey was performed, and survey data were then compared to LiDARderived data. The study found that elevation errors increased with increasing slope and denser vegetation (21). A year prior to this, Hodgson et al. (2004) did a similar study on a watershed in South Carolina, but during a leaf-on period, and they created an error budget model. Elevation error was found to be twice as large on steep slopes as on low slopes (20).

Another drawback to LiDAR is its inability to detect culverts. Hans et al. (2003) determined that without culvert features, small-scale elevation models may not accurately delineate watersheds. Hans et al. (2003) studied the difference between LiDAR data and USGS elevation data to evaluate if there was a significant difference in drainage patterns and to determine whether using LiDAR data improves watershed delineation and the design of culverts. The study found that highresolution DEMs did not significantly impact hydraulic design, but that LiDAR can in some cases provide valuable information for modeling drainage areas of modified terrains such as roads and drainage channels (38). Baily et al. (2008) also did a LiDAR study on drainage structures. LiDAR data was assessed for use in identifying and mapping hedgerows, ditches, and terraces. The overall accuracy of the mapping was about 70\%. In particular, the ditch omission rate was about $50 \%$, due to the use of LiDAR and the presence of dense vegetation in the ditches (18).

Mayfield (2015) raises a question in his article, "The Mapping Match: LiDAR v. Traditional Topo," that is also asked herein: "Can we replicate the accuracy of boots-on-the-ground topographic surveying with airborne LiDAR Technology?" (7). Mayfield's (2015) company was hired by the federal government to map the largest dike system in the southeastern United States, first topographically through conventional field surveys and then by LiDAR. Though his goal was not 
to conduct a comparative analysis, it was evident that LiDAR was a feasible alternative to topographic maps and field surveys. Mayfield (2015) suggests from results that LiDAR could replace conventional surveys.

Table 1 shows the comparison of time spent in Mayfield's (2015) study. The size of the area of interest of the two methods was different, but Mayfield (2015) reported the results in terms of total hours and also on a per mile basis. Mayfield's results ultimately show it takes significantly more time to conduct a field survey using conventional means than by using ab airborne LiDAR survey.

Table 1. Comparison of Time Spent to create map of dike system using conventional surveying methods vs. LiDAR surveying (adapted from 11)

\begin{tabular}{|l|c|c|}
\hline & $\begin{array}{c}\text { Conventional Survey } \\
(25 \text { miles })\end{array}$ & $\begin{array}{c}\text { Airborne Lidar Survey } \\
\text { (153 miles) }\end{array}$ \\
\hline Field Survey Work & 1,344 & 103 \\
\hline Airborne Survey Work & 0 & 154 \\
\hline Office Data Processing Labor & 577 & 373 \\
\hline Total Hours & 1,921 & 2.44 \\
\hline Hours Per Line Mile & 76.84 & \\
\hline
\end{tabular}

Having provided a brief history of the NRCS and conservation management in Oklahoma, and a brief overview of the use of LiDAR in watershed management, the remainder of this report will discuss the data, methods, results, and recommendations of this study to assess the potential impacts of replacing topographic maps with LiDAR data for hydrologic analysis of small watersheds. 


\section{Data \& Methods}

\subsection{Study Setting and Overview}

This case study was conducted on watersheds in Noble County, Oklahoma. The county, as shown in Figure 3, has an area of 742 square miles, lying within the Osage Plaines/ Red Bed Plains region. The landscape is primarily grassy uplands (9). The northern half of the county is nearly level with gentle uplands, while the southern half consists mainly of steep uplands (33). It also contains the bottom lands of two major creeks, Red Rock Creek in the north and Black Bear Creek in the south (9). The northeastern part of the county is bordered by the Arkansas River, and most of the county drains east to this river. Stillwater Creek drains the southeastern part of the county, while Red Rock Creek drains the eastern part and Black Bear Creek the western part. The elevation range of the county is from 840 feet in the northeastern part of the county to 1,270 feet in the southwestern part of the county. Perry, the location of the field service office where this study was done, is the county seat (33).

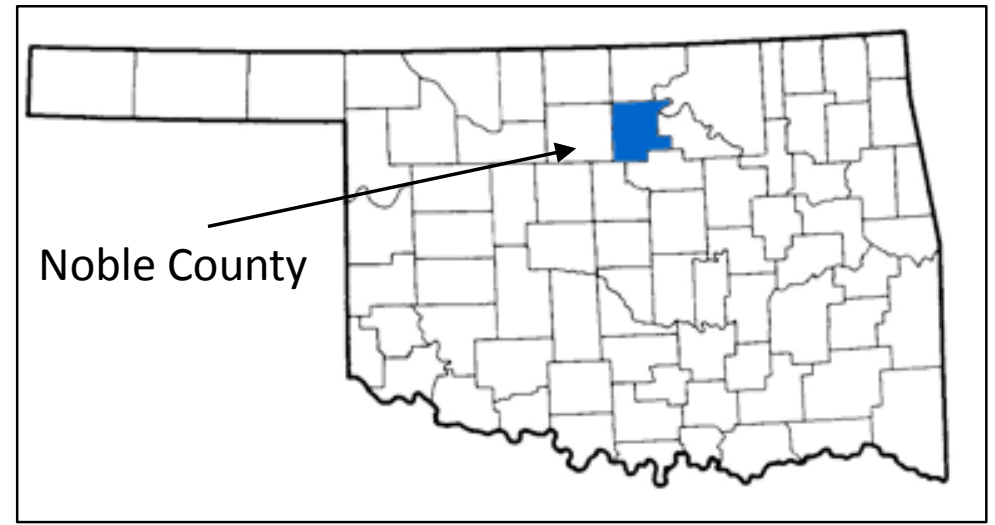

Figure 3. Noble County, Oklahoma (adapted from 5)

After permission was obtained from NRCS Oklahoma to conduct this study, design notes were obtained for 30 randomly selected grassed waterways in the case study area. A spreadsheet was created to compile the parameters of interest (year, drainage area (acres), watershed slope (\%), runoff depth for 10-yr storm (inches), peak flow (cfs), and full time of concentration (hrs)) from 
the design notes. Two columns were created next to each parameter for later input of the same data derived using the LiDAR method.

Geographic information systems (GIS) software (specifically, ArcGIS 10.0 and 10.3) was used to access the aerial vien' of 28 grassed waterway structures. (Two grassed waterways were indiscernible in the design notes as well as in ArcGIS.) NRCS Engineering Tools version 1.1.7 was used to delineate the watershed using 2012 LiDAR data for each structure twice. The geodata layers used are listed in Table 2. Geodata layers are digital renderings of various types of spatial information.

Table 2. Geodata layers

\begin{tabular}{|l|l|l|}
\hline Layer & Brief Description & Data Type \\
\hline World_Imagery & World map & ArcGIS Map Service \\
\hline Noble County Sections & Noble County map & Shapefile feature class \\
\hline soilmu_a_oko103 & NRCS Soil data & Shapefile feature class \\
\hline drg_s_ok103.sid & Noble Topographic map & File system raster \\
\hline * NobleBE & LiDAR derived DEM & File system raster \\
\hline
\end{tabular}

*Field service offices with LiDAR data should inquire within their office for the location of their counties' LiDAR data.

The NRCS is a member of the National Digital Elevation (NDE) Program. As such, the agency is in partnership with the U.S. Geological Survey (USGS ) and uses the USGS LiDAR Base Specifications version 1.0 (also known as LiDAR Base Specification) as the standard for data collection (31). Specifications of the LiDAR data are as follows:

- The defined project area was buffered by a minimum of 100 meters.

- $\quad$ The minimum acceptable quality level was QL2.

- A minimum of 3 returns per pulse was required in all collection efforts.

- Full waveform data was acceptable but supplemental information.

- Intensity values were required for each multiple discrete return and normalized to 16 bit. 
- Nominal pulse spacing (the estimated average spacing between LiDAR points)-representing a single instrument, a single swath, and first return only,--was predicted using flight planning software or calculated by delineating a 1 square kilometer polygon.

- Data voids (gaps in the point cloud caused by surface absorbance or refraction) within a single swath were not acceptable unless caused by water bodies, by areas of low near infrared reflectivity (i.e. asphalt or composition roofing), or appropriately filled by another swath.

- The spatial distribution of points was uniform and regular. At least $90 \%$ of the cells (1 m spatial resolution) contained at least one LiDAR point.

- Only swaths were used with the first return points located within mathematically accepted and thus useable center.

- Atmospheric conditions were cloud and fog free. The ground was snow and flood free, and free of any other accumulation (17).

With the workspace properly set up, the NRCS Engineering Toolbox Watershed tool was used to delineate the watershed using a LiDAR-derived digital elevation model (DEM). Data from that rendering was then used to calculate time of concentration, peak flow, and runoff depth using an Engineering Field Tool (EFT) limited to use by Oklahoma NRCS employees only. EFTs are essentially spreadsheet-based software programs that facilitate data entry and analysis with engineering equations commonly used by NRCS field office technicians and engineers. JMP Pro 12 , a statistical analysis program, was then used to carry out the quantitative analysis of the data.

\subsection{Fundamental Calculations}

Using the topographic method, area is calculated by one of two methods--the dot-grid method or the planimeter method. In the dot-grid method, a topographic map with the delineated watershed is spread on a flat surface and a sheet of mylar with dots in a grid is placed over the area of interest. The dots that fall within the watershed area are counted and multiplied by a factor. Alternatively, a device known as a planimeter can be used to measure watershed area. It has two arms, where one is fixed and the other attached to a magnifying lens with a pointer. 
The topographic map is again spread on a flat surface, and the base of the planimeter is placed in a location that will allow the user to trace around the perimeter of area of interest with the pointer. A dial records the area. Dot grids tend to be more affordable than planimeters (5). Green's theorem, which relates the line integral of the boundary to the double integral of the closed region, best explains how what the dial records is equivalent to the area of the enclosed region (22).

Slope is the change in elevation per unit distance (1). Using the topographic method, the average watershed slope is calculated by measuring the lengths of all contour lines within the watershed:

$$
\text { Slope }(\%)=\frac{100(C I)}{A} \quad \text { [eq. 1] }
$$

where $\mathrm{C}$ is the summation of the contour lines that pass through watershed drainage area in feet, $I$ is the interval of the contour lines in feet, and $A$ is drainage area in square feet. Along any transect, slope (\%) can be calculated as the vertical distance (rise) divided by the horizontal distance (run) and multiplied by

In the LiDAR method, the NRCS watershed tool in ArcMap calculates drainage area using flow direction and flow accumulation raster (grid) data layers. The flow direction grid is illustrated in Figure 4. This grid indicates the direction of flow for each cell in the raster, assuming each cell has the possibility of flowing in one of eight directions. The steepest descent determines the flow direction for each cell (14). The corresponding flow accumulation grid is shown in Figure 5. Accumulated flow is calculated for each grid cell as the total number of upstream cells flowing downslope, as previously determined by the flow direction grid (13).

In the LiDAR method, slope (\%) is calculated in ArcMap using the Spatial Analyst extension. There are many different methods available to calculate slope using geographical information systems (GIS). In ArcMap, the slope tool generally finds slope based on elevations in a 3x3 neighborhood around a centrally located processing cell. Based on the z-values of the target cell and 8 surrounding cells, a plane is fit to the z-values and slope is calculated using the average maximum 
technique. The plane will be flatter for lower slope values and steeper for higher slope values. If a cell in the neighborhood is without a $z$-value, or if is beyond the edge of the raster, the value of the center processing cell is used. Figure 6 below illustrates an input raster and output raster of this process (11).

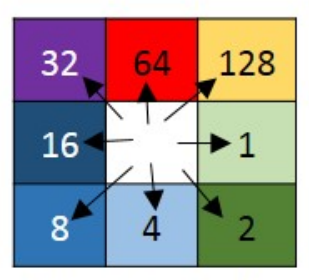

Direction Coding

\begin{tabular}{|l|l|l|l|l|l|}
\hline 78 & 72 & 69 & 71 & 58 & 49 \\
\hline 74 & 67 & 56 & 49 & 46 & 50 \\
\hline 69 & 53 & 44 & 37 & 38 & 48 \\
\hline 64 & 58 & 55 & 22 & 31 & 24 \\
\hline 68 & 61 & 47 & 21 & 16 & 19 \\
\hline 74 & 53 & 34 & 12 & 11 & 12 \\
\hline
\end{tabular}

Elevation Surface

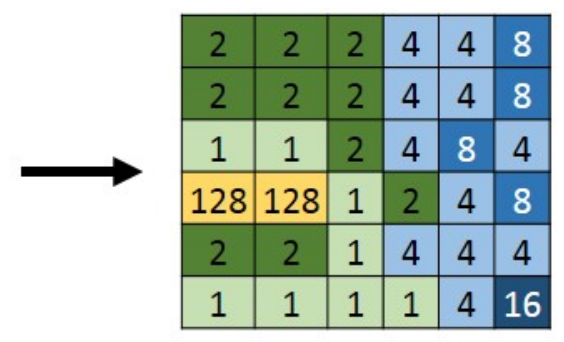

Flow Direction

Figure 4. Flow direction grid (adapted from 14)

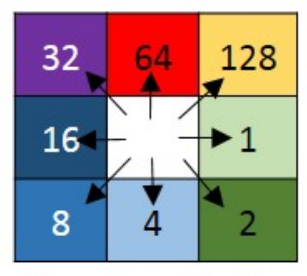

Direction Coding

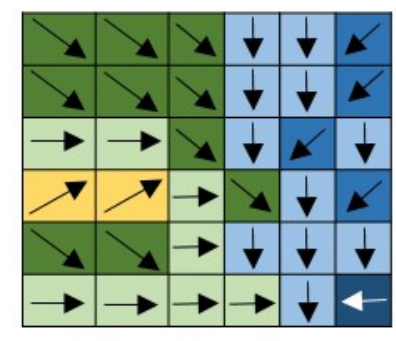

Flow Direction

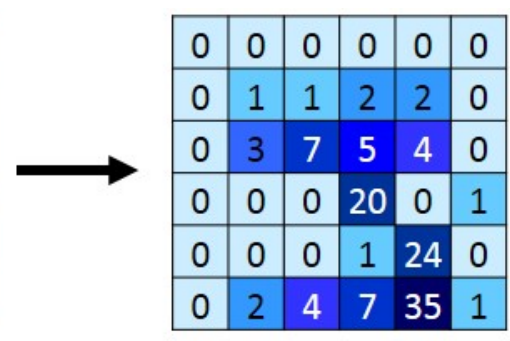

Flow Accumulation

Figure 5. Flow accumulation grid (adapted from 13)

\begin{tabular}{|l|l|l|l|l|l|}
\hline 1 & 1 & 1 & 1 & 1 & 1 \\
\hline 1 & 3 & 3 & 2 & 1 & \\
\hline 1 & 1 & 3 & 2 & 2 & 2 \\
\hline 1 & 2 & 2 & 2 & 2 & 2 \\
\hline 1 & 1 & 1 & 2 & 2 & 2 \\
\hline 1 & 1 & 1 & 1 & 1 & 2 \\
\hline
\end{tabular}

Input

$=$\begin{tabular}{|c|c|c|c|c|c|}
\hline 19.5 & 38.3 & 41.5 & 29.2 & 10.0 & 0.0 \\
\hline 26.6 & 38.3 & 32.5 & 41.5 & 29.2 & \\
\hline 21.6 & 43.6 & 21.6 & 26.6 & 14.0 & 10.0 \\
\hline 14.0 & 29.2 & 29.2 & 14.0 & 0.0 & 0.0 \\
\hline 10.0 & 21.6 & 29.2 & 29.2 & 21.6 & 10.0 \\
\hline 0.0 & 0.0 & 10.0 & 21.6 & 29.2 & 14.0 \\
\multicolumn{5}{|c}{ Output }
\end{tabular}

Value $=$ No Data

Figure 6. Example of slope calculation in ArcGIS Spatial Analyst tool (adapted from 12) 


\subsection{Engineering Field Tool Equations}

The NRCS Engineering Field Tool (EFT) uses a set of equations for peak discharge computations that is standard to the NRCS. Specifically, the time of concentration $\left(T_{c}\right)$ can be found using the NRCS lag equation, multiplied by a factor, as displayed in Equations 2 and 3. The time of concentration is the amount of time it takes for a water particle to travel from the farthest point in the watershed to the designated outlet. In the watershed lag method, developed by the NRCS in 1961 (32), the lag (L), or the time from when runoff begins until it reaches a peak, is estimated to be $0.6 T_{c}$.

$$
\begin{aligned}
& L=\frac{l^{0.8}(S+1)^{0.7}}{1,900 Y^{0.5}} \\
& T_{C}=\frac{l^{0.8}(S+1)^{0.7}}{1,140 Y^{0.5}}
\end{aligned}
$$

where $S=$ potential abstraction which is equivalent to $(1000 / C N)-10$, where $C N$ is the runoff curve number; $I=$ hydraulic flow length in feet, which can be estimated as $209 A^{0.6}$, where $A$ is area in acres; and $Y=$ average slope in percent, which is given by Equation 1 as a function of drainage area and the summation of contour lengths.

Following the NRCS Runoff Curve Number method, runoff volume (in units of depth over the watershed) can be found using the weighted average $\mathrm{CN}$ value to compute $S$ in equation 4:

$$
\mathrm{Q}=\left((\mathrm{P}-0.2 \mathrm{~S})^{2}\right) /(\mathrm{P}+0.8 \mathrm{~S}) \quad \text { [eq. 4] }
$$

where $Q=$ runoff depth in inches $P=$ rainfall or design storm depth in inches, and $S=$ potential abstraction in inches, as defined above.

Finally, the peak discharge, $q_{p}$, can be found using NRCS Peak Discharge Method equation 5:

$$
q_{p}=Q * q_{u} * A \quad \text { [eq. 5] }
$$

where $q_{p}=$ peak flow in cfs, $\mathrm{Q}=$ runoff volume in inches, $\mathrm{A}=$ drainage area in acres, and $q_{u}=$ unit peak discharge in cfs/acre/inch, where $q_{u}$ is found using the NRCS TR-55 Graphical Peak Discharge Method. After Initial abstraction la is found, Ia/P, where P is rainfall (24 hours), is computed and used along with $\mathrm{T}_{c}$ to graphically determine $q_{u}$. 


\subsection{NRCS Watershed Tool}

There were three main steps to delineating the watershed using the NRCS Engineering Toolbox Watershed tool, and there was one additional step to determine the area of each soil type in the watershed. First, to define the area of interest, a box is drawn by the user over the area surrounding the grassed waterway, as shown in Figure 7. Next, the stream network is created for the area of interest, as shown in Figure 8. If there are culverts present, they are defined during this step. The program is executed, and the stream networks within the area of interest are created. Lastly, the watershed is created by selecting the stream networks created in the previous step. The program is executed, and the boundary of the watershed is drawn for the specified outlet, as shown in Figure 9. To determine the acres of each soil type in the watershed, the user selects the "Prepare soils and landuse" option. See the appendix for more detailed step-by-step instructions of this procedure.

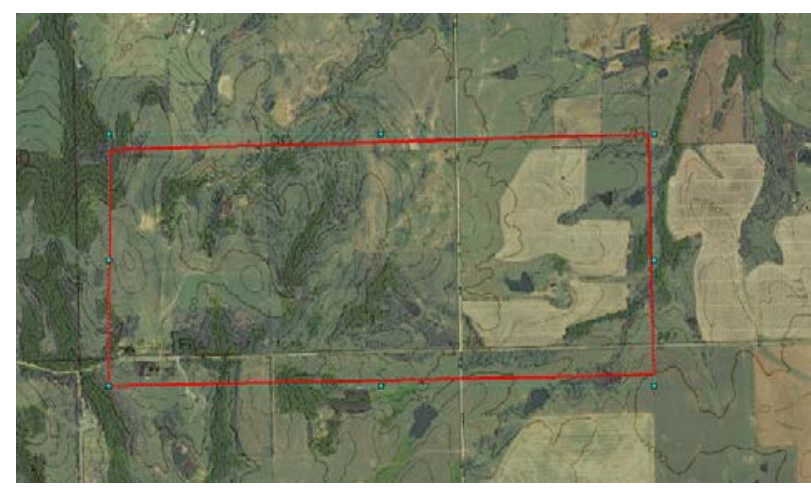

Figure 7. Boundary drawn to define area of interest Figure created by author using ArcGIS

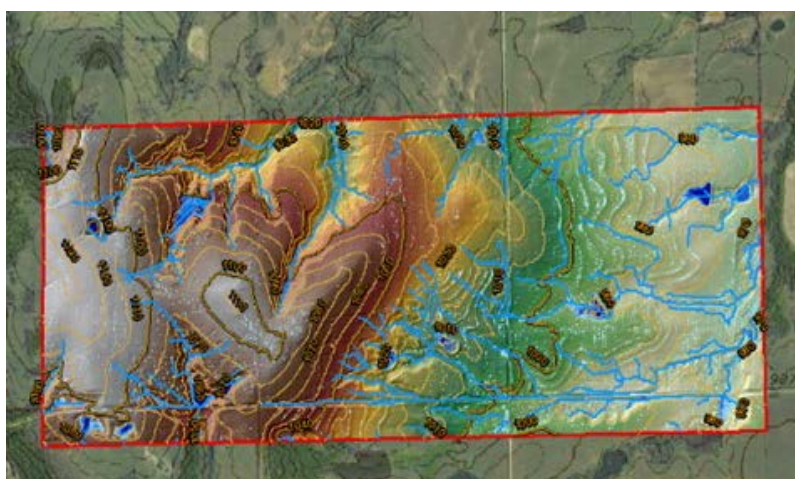

Figure 8. Stream network being created Figure created by author using ArcGIS

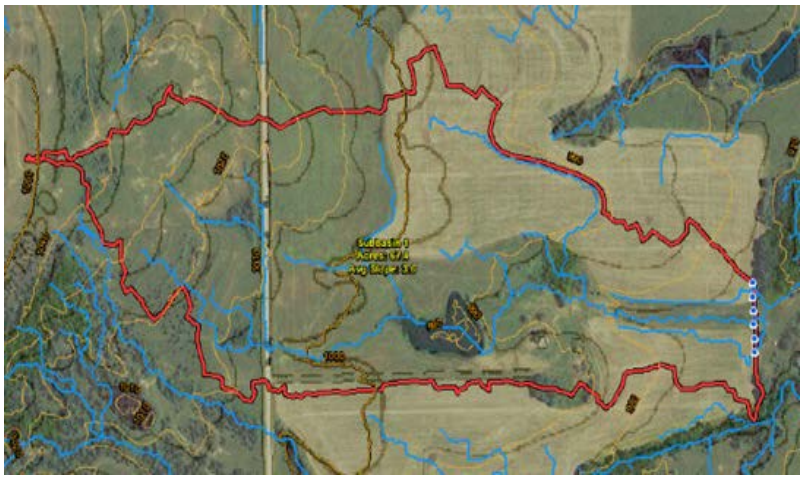

Figure 9. Boundary of watershed being drawn Figure created by author using ArcGIS 


\section{Results \& Discussion}

There is a strong linear association between the drainage areas found by the topographic method and the LiDAR method, as shown in Figure 10. The mean for the topographic method was 65.32 acres and the standard deviation 66.50 acres. The mean for the LiDAR method was 69.61 acres and the standard deviation 69.88 acres. Based on these results, there is not a significant difference between the means $(p=0.8148)$. However, the drainage areas for landowner 10 were vastly different. In the design notes, landowner 10 had a drainage area of 20 acres based on the topographic method. By the LiDAR method, Landowner 10 had 141 acres. This is an instance where field verifications would have to be done to determine precisely why these two numbers are so different, but a possible reason is that the placement of the watershed outlet was inconsistent in the two methods.

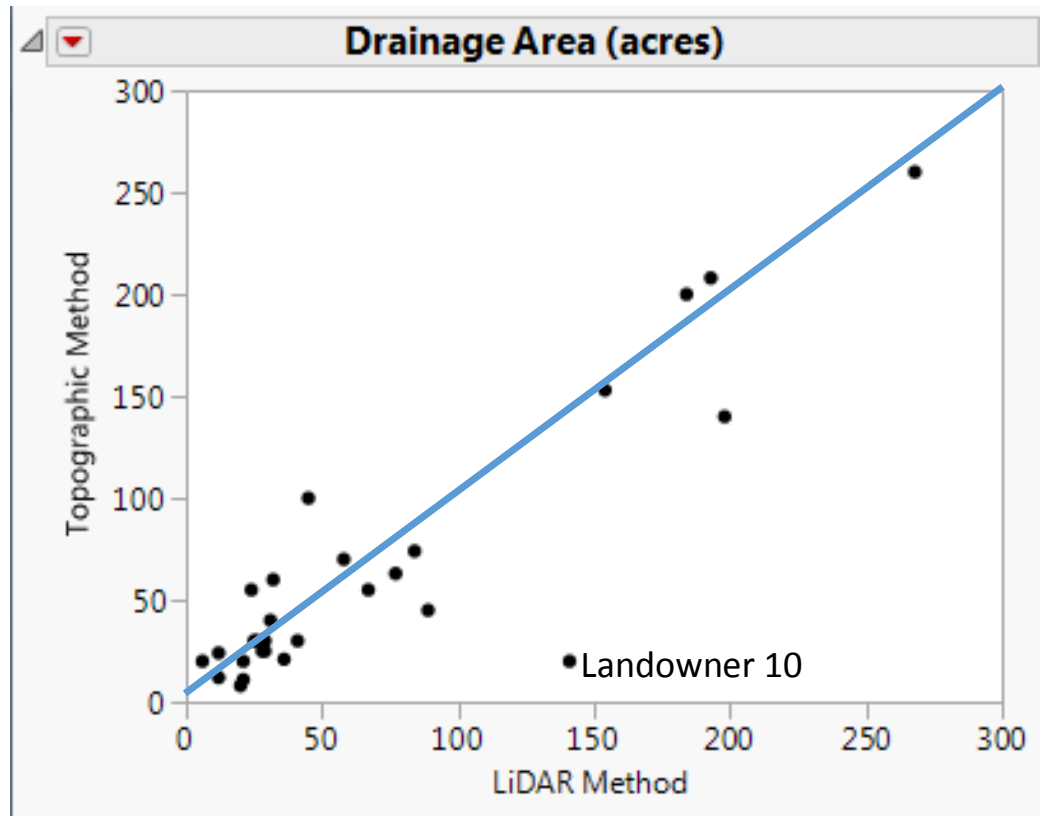

Figure 10. Drainage area results. Landowner 10 an outlier data point shown. (Figure created by author using JMP Pro 12)

Since grassed waterways are continuous structures, as one moves the outlet downstream the drainage area of the watershed increases. Moving the outlet farther up the waterway in ArcGIS using the LiDAR method decreases the resulting drainage area. Also, the LiDAR method considers 
more or less drainage area based on the stream networks the designer selects, while the topographic method relies on the designer's skill at interpreting the contour lines.

In contrast to the drainage areas, there is a weak linear correlation between the average watershed slopes found by the topographic method and the LiDAR method, as shown in Figure 11. The mean for the topographic method was $2.09 \%$ and the standard deviation $0.72 \%$, while the mean for the LiDAR method was $3.20 \%$ and the standard deviation $0.77 \%$. There is an significant difference between the means $(p=0.0001)$. The LiDAR method slopes are significantly higher than slopes based on the topographic method, as shown in Figure 11.

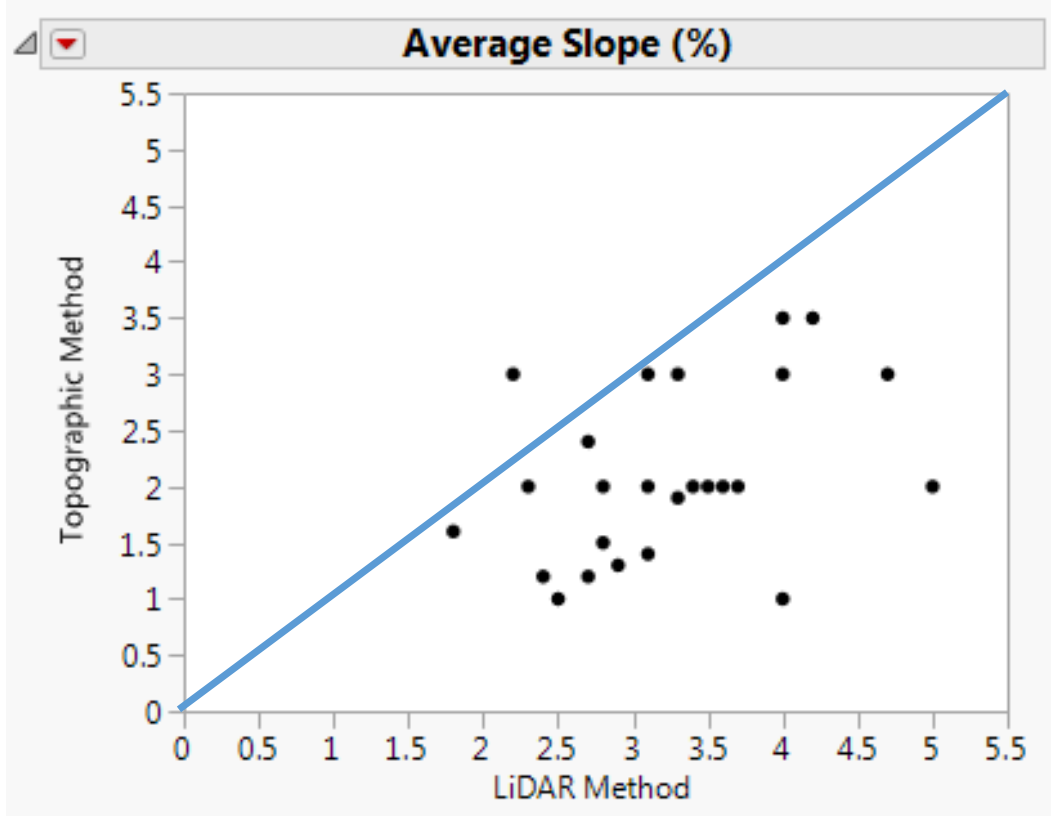

Figure 11. Average slope results

(Figure created by author using JMP Pro 12)

The steepness of the watershed inversely affects the time of concentration of the runoff, and thus how slope is calculated is significant in watershed hydrologic studies. It was discovered in this study that when slope is calculated simply using the rise over run method, terrain features such as hills, valleys, and ridges can go unaccounted for. This may be why the NRCS uses the summation of the contour lines method. 
There is a moderately strong linear association between the time of concentration found by the topographic method and the LiDAR method, as shown in Figure 12. The mean for the topographic method was 0.77 hours and the standard deviation 0.48 hours, while the mean for the LiDAR method was 0.61 hours and the standard deviation 0.30 hours. There is not a significant difference in the two means $(p=0.1405)$. The time of concentration calculated from the topographic method tended to be higher or about the same as the time of concentration calculated from the LiDAR method, due to differences in drainage area and larger differences in slope. There were only a few instances where the LiDAR method was higher. For Landowner 6 site A, this was due to larger drainage area and larger slope, while for Landowner 6 site B it was due to larger slope only (drainage areas were equivalent), and for Landowner 10 it was due to vastly larger drainage area (slope by the topographic method was $31 \%$ less than the slope by the LiDAR method).

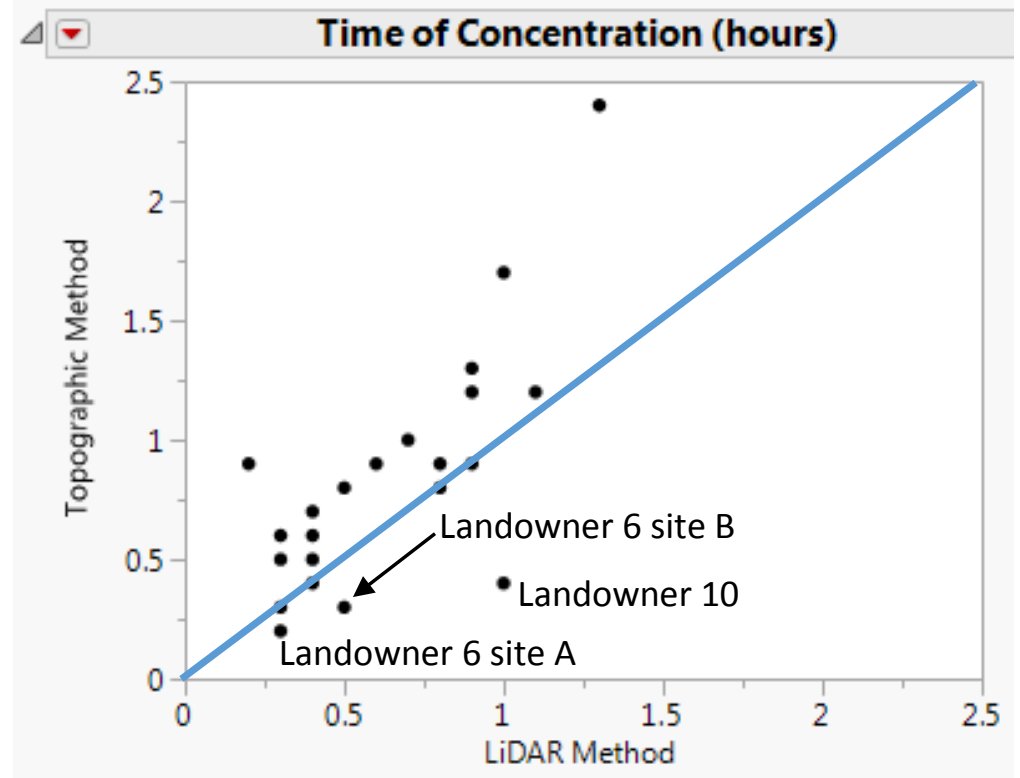

Figure 12. Time of concentration results

(Figure created by author using JMP Pro 12)

There is a moderate association between the runoff depths found by topographic method and the LiDAR method, as shown in Figure 13. The mean for the topographic method was 3.32 inches and the standard deviation 0.46 inches, and the mean for the LiDAR method was 3.35 inches and the standard deviation 0.37 inches. There is not a significant difference in the means $(p=0.7890)$; 
however, absolute differences can be significant. The $+/-20 \%$ difference of runoff is mainly due to the difference in drainage area as well as runoff curve numbers.

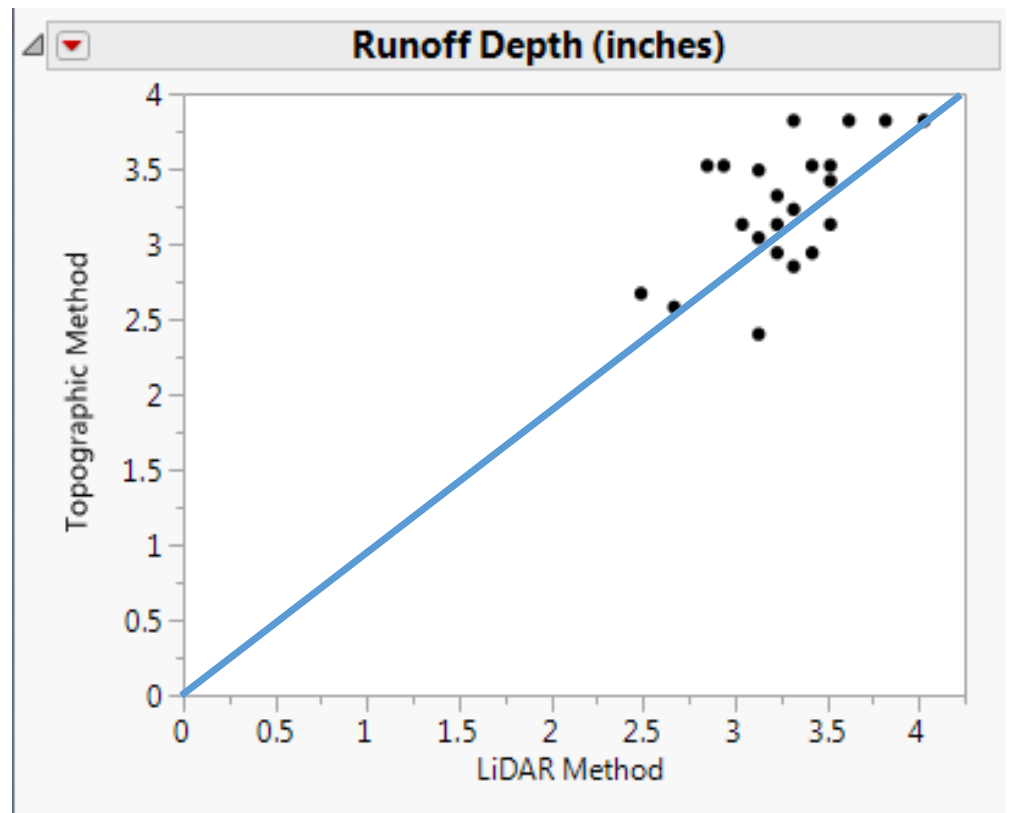

Figure 13. Runoff Depth results

(Figure created by author using JMP Pro 12)

Finally, there is a strong linear association between the peak flows found by the topographic method and the LiDAR method, as shown in Figure 14. The mean for the topographic method was $122.21 \mathrm{cfs}$ and the standard deviation $86.76 \mathrm{cfs}$, and the mean for the LiDAR method was $155.21 \mathrm{cfs}$ and the standard deviation $115.30 \mathrm{cfs}$. There is not a significant difference in the means ( $p=0.2315)$, and again Landowner 10 is an outlier. Peak flow is a critical parameter in the design of grassed waterways, since it is used to determine the maximum capacity of the structure. The peak flow calculated from the topographic method tended to be lower than the peak flow calculated from the LiDAR method primarily due to slope and time of concentration differences. There were a few instances where the topographic method gave a higher peak flow, due to differences in drainage area and curve number. 


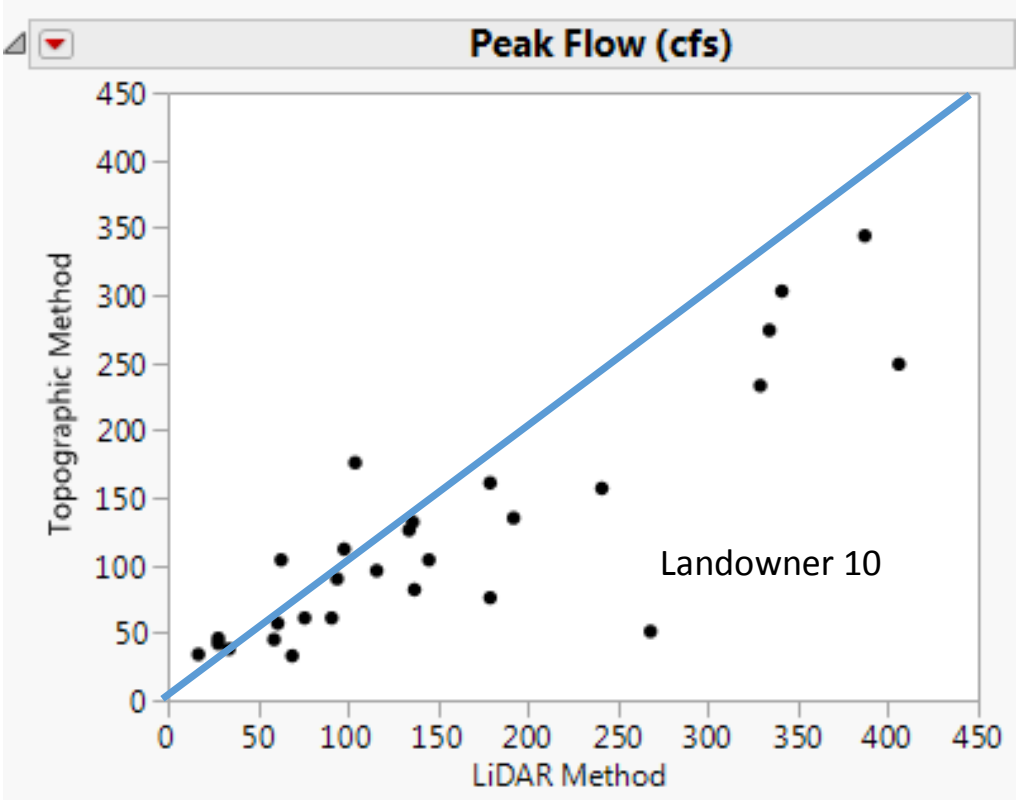

Figure 14. Peak flow results. Landowner 10

an outlier data point shown. (Figure created by author using JMP Pro 12).

Table 3 below displays the absolute percent difference and the mean percent difference of the parameters. The mean percent differences for drainage area and runoff depth were low, but the absolute percent differences for the two parameters were significantly higher. For slope, both the mean and absolute differences were significantly high, which leads to large differences in time of concentration and peak flow as well. Ultimately, caution must be used in applying LiDARbased elevation data (with attention given particularly to slopes) in the design of hydraulic structures such as grassed waterways.

Table 3. Mean \% difference and mean absolute \% difference of parameters computed by topographic and LiDAR method

\begin{tabular}{|l|c|c|c|c|c|}
\hline \multicolumn{1}{|c|}{ Parameter } & $\begin{array}{c}\text { Drainage } \\
\text { Area }\end{array}$ & $\begin{array}{c}\text { Average } \\
\text { Slope }\end{array}$ & $\begin{array}{c}\text { Time of } \\
\text { Concentration }\end{array}$ & $\begin{array}{c}\text { Runoff } \\
\text { Depth }\end{array}$ & $\begin{array}{c}\text { Peak } \\
\text { Flow }\end{array}$ \\
\hline Mean Absolute \% difference & 37.83 & 45.90 & 39.67 & 7.48 & 35.41 \\
\hline Mean \% difference & 2.66 & 43.70 & -18.14 & 1.43 & 15.39 \\
\hline
\end{tabular}




\section{Conclusion}

Grassed waterways reduce the impacts of agricultural land use. By increasing infiltration and reducing the velocity of runoff, they reduce the volume of runoff flowing to dams, and they effectively reduce erosion from cultivated fields flowing to dams as well (24).

Several hydrologic parameters critical to the design of grassed waterways were analyzed in this study using a conventional topographic map-based method and LiDAR derived digital elevation data. The parameters analyzed were drainage area (acres), average slope (\%), time of concentration (hours), runoff depth (inches) for the 10-year design storm, and peak flow (cfs). By evaluating these parameters, it was possible to determine how the two different methods can impact the hydrologic design of selected grassed waterways.

Although results of the two methods are fairly comparable overall, it was shown that switching to the LiDAR-based method can impact the hydrologic design of grassed waterways. Notably, the LiDAR method yielded higher slopes, which caused lower time of concentration values and thus higher peak flows on average. As long as the drainage outlet is agreed upon, however, the LiDAR method is expected to give more consistent and potentially more accurate estimates of drainage area and thus runoff volume. As pointed out by Amatya et al. (2013), DEMs should be used to create more accurate boundary drainage areas for the improvement of subsequent hydrologic calculations. Attention should be given to slope calculations, however, since the average watershed slope produced in the LiDAR method may be overestimated for low slopes, as seen in this study. Until further study can be done, it is recommended that the topographic method be used in conjunction with the LiDAR method as a means for checking and adjusting for the slope error that arises in the LiDAR method. 


\section{Works Cited}

1. (2016, Feb. 12) "Chapter 3 Watershed Hydrology" [online] Available:

www.hydrology.uga.edu/rasmussen/class/4500/ch3.pdf

2. (2016, Feb. 9) "Raster Data and Vector Data", (City of High Point North Carolina), [online] Available: http://www.highpointnc.gov/gis/raster_v_vector_data.cfm

3. (2016, Mar. 5) "Perry CCC Lake \& Park" [online] Available:

http://www.blogoklahoma.us/place.aspx?id=835

4. (2016, Mar. 8) "Grassed waterway Missouri.jpg" [online] Available:

https://commons.wikimedia.org/wiki/File:Grassed_waterway_missouri.jpg

5. A. Ammann and A.L. Stone (1991) "How to Read a Topographic Map and Delineate a Watershed" NRCS, NH 1991 [Online] Available: http://www.nrcs.usda.gov/Internet/FSE_DOCUMENTS/nrcs144p2_014819.pdf

6. A. T. Hudak, J.S. Evans, A.M.S. Smith (2009) “ LiDAR utility for natural resource managers" Remote Sensing [Online] 1, pp 934-951 Available: http://www.treesearch.fs.fed.us/pubs/34574

7. B. Mayfield (2015, Nov. 1) "The Mapping Match: LiDAR v. Traditional Topo" (Point of Beginning), [Online]. (2015) Available: http://www.pobonline.com/articles/97670-themapping-match-LiDAR-v-traditional-topo

8. D. Amatya, C. Trettin, S. Panda, H. Ssegane (2013) "Application of LiDAR data for hydrologic assessments of low-gradient coastal watershed drainage characteristics" Journal of Geographic Information Systems [Online] 5(2), pp. 175-191. Available: http://www.treesearch.fs.fed.us/pubs/44385

9. D. Everett (2016, Feb. 29) "Noble County." (Encyclopedia of Oklahoma History and Culture), [online] Available:

http://www.okhistory.org/publications/enc/entry.php?entry=NO003

10. E.L. Usery, D. Varanka, M.P. Finn (2015, Jan. 12) “A 125 Year History of Topographic Mapping and GIS in the U.S. Geological Survey 1884-2009, Part 1 1884-1980" (USGS) 2013, Available: http://nationalmap.gov/ustopo/125history.html.

11. Esri (2016, Feb. 25) "How Slope works", (ArcGIS Pro), [online] Available: http://pro.arcgis.com/en/pro-app/tool-reference/3d-analyst/how-slope-works.htm 12. Esri (2016, Feb. 25) "Slope", (ArcGIS Pro), [online] Available: http://pro.arcgis.com/en/pro-app/tool-reference/3d-analyst/slope.htm 
13. Esri (2016, Feb. 9) "How Flow Accumulation works", (ArcGIS Pro), [online] Available: http://pro.arcgis.com/en/pro-app/tool-reference/spatial-analyst/how-flowaccumulation-works.htm

14. Esri (2016, Feb. 9) "How Flow Direction works", (ArcGIS Pro), [online] Available: http://pro.arcgis.com/en/pro-app/tool-reference/spatial-analyst/how-flow-directionworks.htm

15. F. D. Phillips and M. S. Harrison, (2004)Out of the Dust The History of Conservation in Oklahoma in the $20^{\text {th }}$ Century. Oklahoma City: OACD 2004 9-11, 47, 55, 56, 61

16. F. Krogstad and P. Schiess (2004) The Allure and Pitfalls of Using LiDAR topography in Harvest and Road Design," Joint Conference of IUFRO 3.06 Forest Operations in Mountainous Conditions and the $12^{\text {th }}$ International Mountain Logging Conference, Vancouver, B.C. Canada.

17. H.K. Heidemann (2014) LiDAR base specification (ver. 1.2, November 2014): U.S. Geological Survey Techniques and Methods, book 11, chap. B4, 67 p. with appendixes, Available: http://dx.doi.org/10.3133/tm11B4.

18. J. S. Bailly , P. Lagacherie, C. Millier , C. Puech , P. Kosuth (2008) “Agrarian landscapes linear features detection from LiDAR: application to artificial drainage networks" International Journal of Remote Sensing. [Online] 29(12). Available: http://www.tandfonline.com/doi/abs/10.1080/01431160701469057

19. K. Chang. Introduction to Geographical Information Systems, $7^{\text {th }}$ ed. New York, NY: McGraw Hill Companies, 2014.

20. M.E Hodgson and P. Bresnahan (2004) Accuracy of Airborne Lidar-Derived Elevation: Empirical Assessment and Error Budget, Photogrammetric Engineering \& Remote Sensing 70(3):331-339

21. M.E. Hodgson, J. Jensen, G. Raber, J. Tullis, B.A. Davis, G. Thompson, K. Schuckman(2005) An evaluation of LiDAR-derived elevation and terrain slope in leaf-off condition. Photogrammetric Engineering and Remote Sensing 71, 817-23. Available: http://eserv.asprs.org/PERS/2005journal/jul/2005_jul_817-823.pdf

22. Mathematica (2016, Mar. 15) “Area Measurement: Planimeters \& Green's Theorem”, (Attewood.com), [online]. 2006 Available: http://www.attewode.com/Calculus/AreaMeasurement/area.htm 
23. OCC "Conservation Programs Division" (OK.gov) 2013, Available: https://www.ok.gov/conservation/Agency_Divisions/Conservation_Programs_Division/F lood_Control_Programs/

24. P. Fiener and K. Auerswald (2003) Effectiveness of grassed waterways in reducing runoff and sediment delivery from agricultural watersheds. J. Environ. Qual. 32(3), pp. 927-36. Available: http://search.proquest.com/docview/197403054?accountid=28041.

25. P.A. Burrough and R.A. McDonnell. Principles of Geographical Information Systems. New York: Oxford University Press, 1998.

26. P.N.C Murphy, J. Ogilvie, F. Meng, P. Arp (2007) “Stream network modelling using LiDAR and photogrammetric digital elevation models: a comparison and field verification". Hydrological Processes [Online] 22(12), pp. 1747-1754. Available: http://onlinelibrary.wiley.com/doi/10.1002/hyp.6770/epdf

27. R.C. Weih, Jr. and T.L. Mattson (2004) Modeling slope in a geographic information system. Proceedings of the Arkansas Academy of Science (58)pp.100-108. Available: http://search.proquest.com/docview/51660423?accountid=28041.

28. S. J. Bennett, C. M. Cooper, J. C. Ritchie, J. A. Dunbar and et al. (2002)“Assessing sedimentation issues within aging flood control reservoirs in Oklahoma". J. Am. Water Resour. Assoc. 38(5), pp. 1307-1323. Available: http://search.proquest.com/docview/201276163?accountid=28041.

29. United States Department of Agriculture Natural Resources Conservation Service, Oklahoma Association of Conservation Districts, Oklahoma Conservation Commission,. GPO.2004. Print

30. United States Department of Commerce, National Oceanic and Atmospheric Administration (2015, Aug.) “What is LiDAR?"(NOAA.gov). [Online]. Available: http://oceanservice.noaa.gov/facts/LiDAR.html

31. USDA “Digital Elevation Data” (NRCS.USDA.gov) [Online]. Available: http://www.nrcs.usda.gov/wps/portal/nrcs/main/national/ngce/elevation/ 
32. USDA and NRCS (2016, Jan. 7) "Chapter 15 Time of Concentration" in Part 630 Hydrology National Engineering Handbook [online] Available:

directives.sc.egov.usda.gov/27002.wba

33. USDA and NRCS. Soil Survey of Noble County, Oklahoma," USDA and NRCS, Noble County, OK

34. USGS (1999) "Map Accuracy Standards” (USGS.gov), [online]. Available: http://pubs.usgs.gov/fs/1999/0171/report.pdf

35. USGS “The National Map: Topographic Maps for the $21^{\text {st }}$ Century" (GPO.gov) 2006 [Online]. Available: http://permanent.access.gpo.gov/lps99074/fs2006-3107.pdf

36. USGS “Topographic Map Symbols” (USGS.gov) [Online]. Available: http://pubs.usgs.gov/gip/TopographicMapSymbols/topomapsymbols.pdf

37. X. Liu, J. Peterson, Z. Zhang (2005) High-resolution DEM generated from LiDAR data for water resource management. In: MODSIM05: International Congress on Modelling and Simulation: Advances and Applications for Management and Decision Making, 12-15 Dec 2005, Melbourne, Australia.

38. Z. Hans, S. Hallmark, R. Souleyrette, R. Tenges, and D. Veneziano (2003) Use of LiDARBased Elevation Data for Highway Drainage Analysis: A Qualitative Assessment. Center for Transportation Research and Education Project 01-98. Final Report. Midwest Transportation Consortium, lowa State University, Ames3. 


\section{Appendix. NRCS Watershed Tool Operation}

This appendix outlines the steps necessary to delineate a watershed using the NRCS Watershed tool.

Step 1: Define the area of interest

- Once the sustainable structure of interest has been located in ArcGIS using the legal descriptions layer, turn on the topographic layer. This layer will help in drawing the boundary of the area of interest later on.

- In ArcToolbox, select NRCS Engineering Tools. Then select Watershed Tools. Under Watershed Delineation, double click "Define Area of Interest" to open the DAI (Define Area of Interest) window (Figure A1). If NRCS Engineering Tools is not already in ArcToolbox, right click Arctoolbox and select "Add Toolbox" and navigate to the location of NRCS Engineering Tools on the computer. The NRCS GIS Engineering Tools ver 1.1.7 zip can be downloaded from this website:

\section{ftp://ftp.Imic.state.mn.us/pub/data/elevation/LiDAR/tools/NRCS engineering/ .}

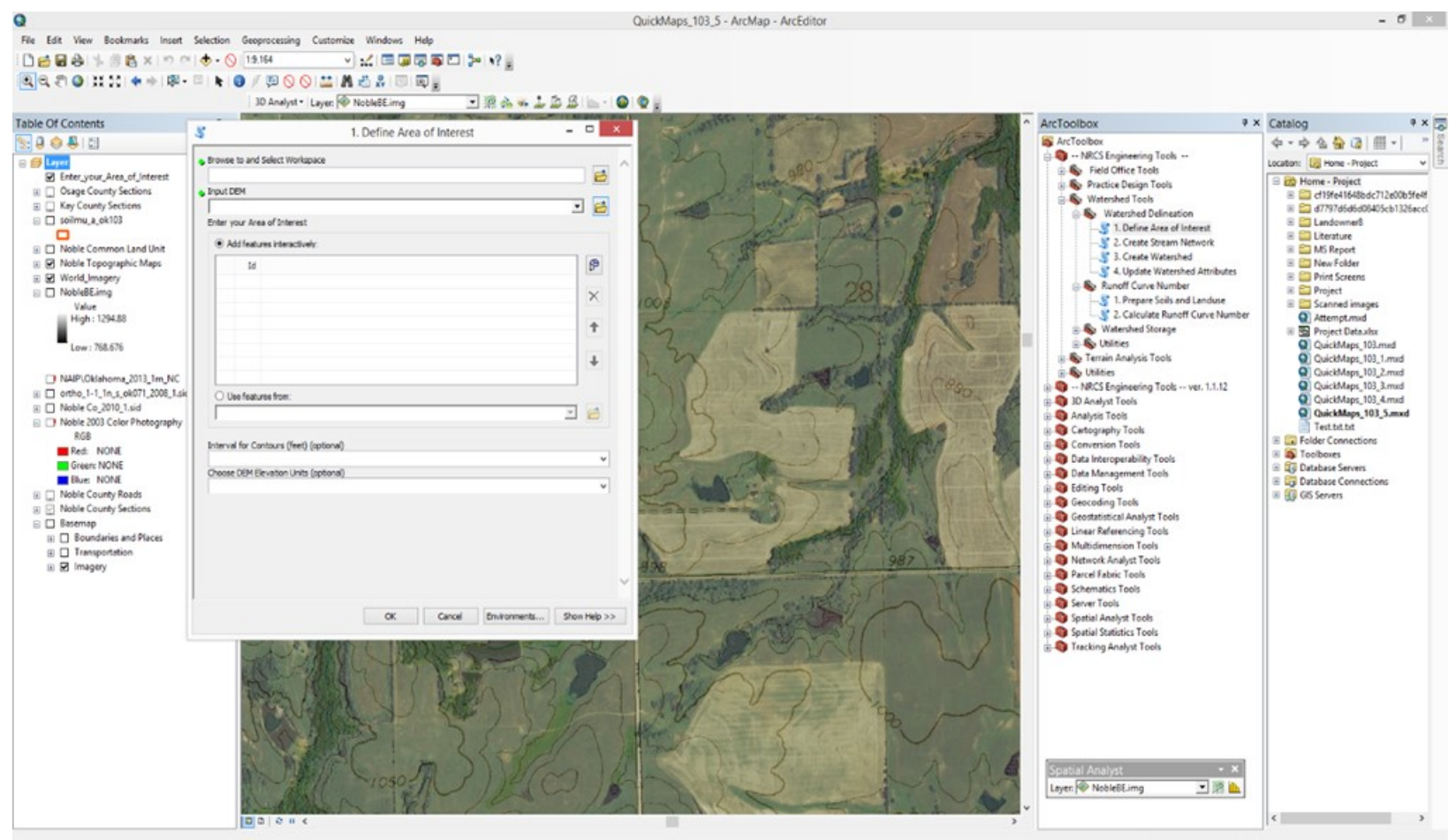

Figure A1. Define Area of Interest Window opening 
- After opening the DAI window, browse to Select Workspace by clicking on the first folder. Once that has been done, navigate to the desired workspace. In this example, the desired workspace was C: \Project\Landowner1 (Figure A2).

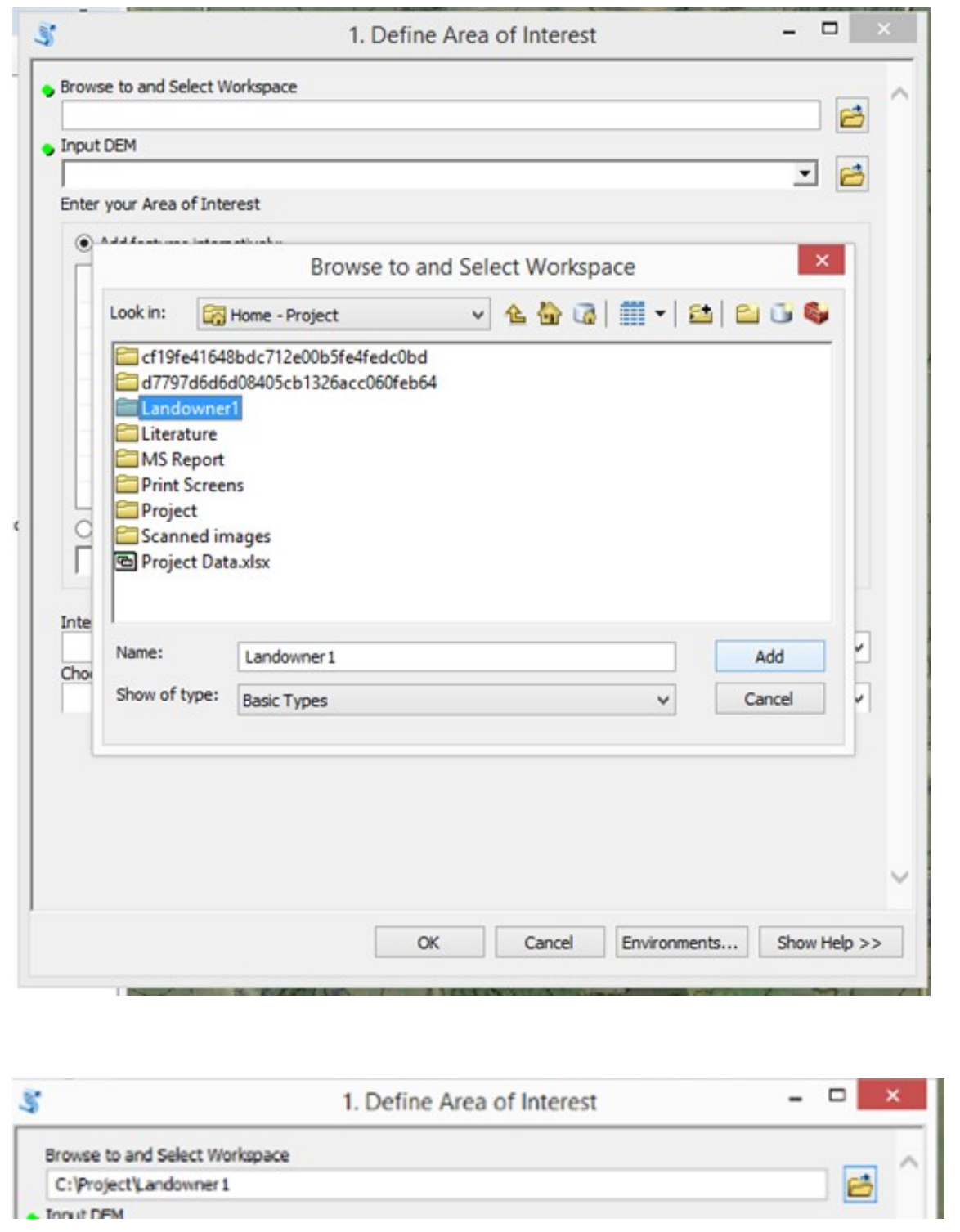

Figure A2. Workspace 
- Next, select the black downward facing arrow next to the manila envelope below the first to navigate through the layers to select the LiDAR data layer. For this project the LiDAR data layer was named NobleBE (BE representing bear earth) and left in .img format. Select LiDAR data layer for Input DEM (Digital Elevation Model), as shown in Figure A3.

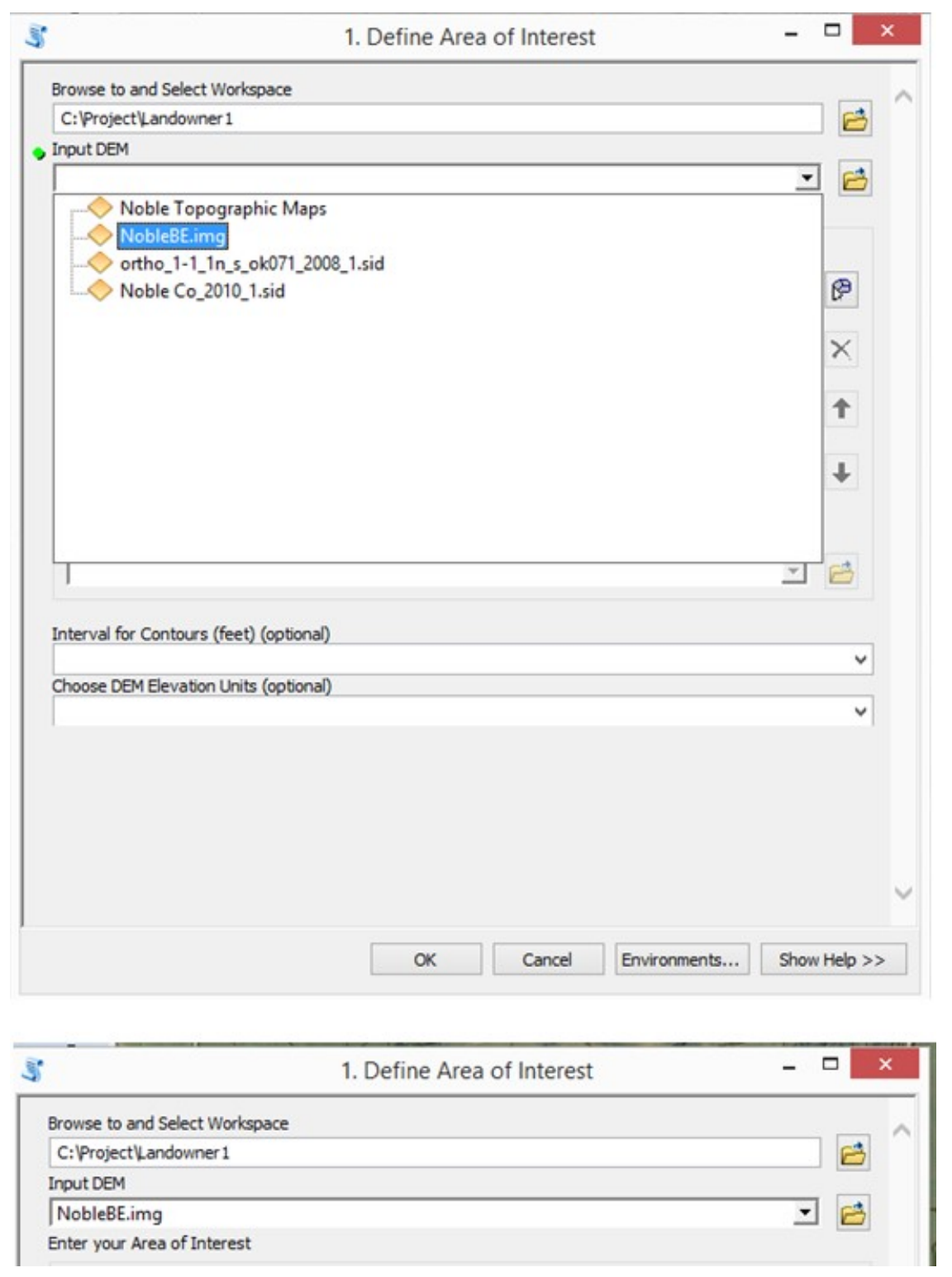

Figure A3. LiDAR data layer for Input DEM 
- Next, select the add feature button to be able to draw the boundary of area of interest (Figure A4). Be sure to minimize the window before doing so to allow for more workspace.

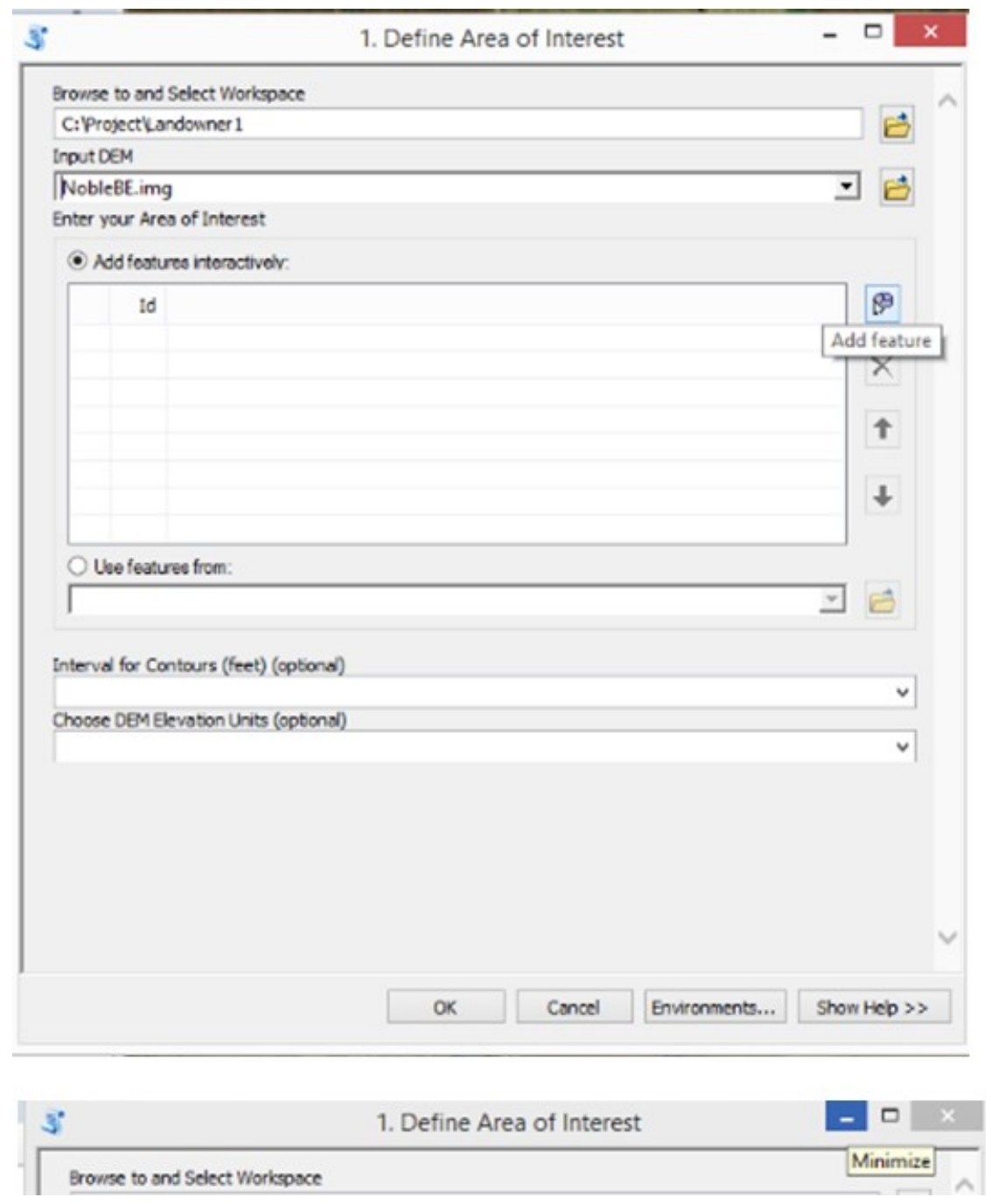

Figure A4. Selecting add feature button 
- Draw the boundary of area of interest with topographic map layer turned on, as shown in Figure A5

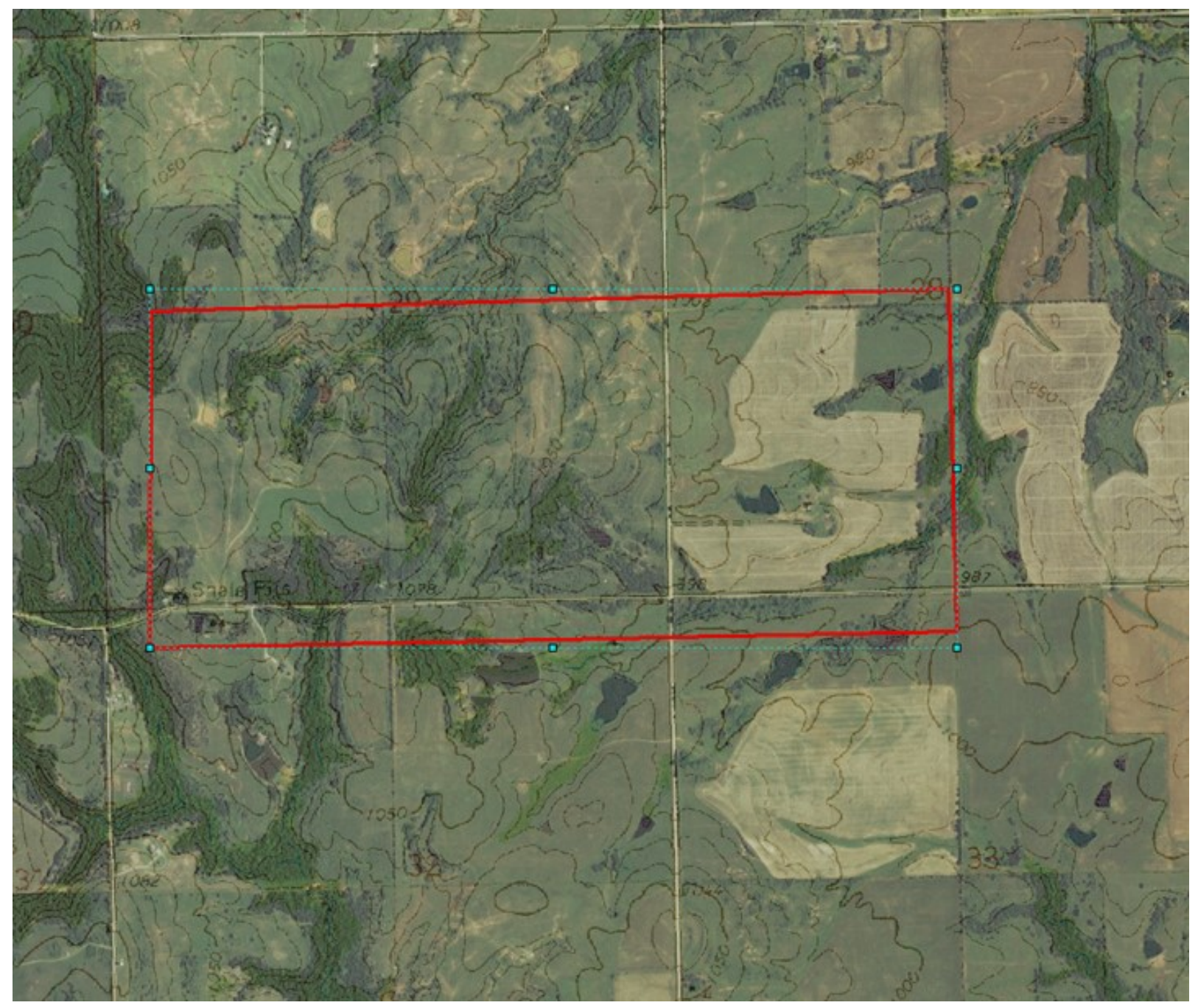

Figure A5.Drawing of boundary of area of interest for grassed waterway 
- Hover over the ArcMap icon (the earth with magnifying glass) in the windows bar running along the bottom of the screen below to access DIA window again, as shown in Figure A6.

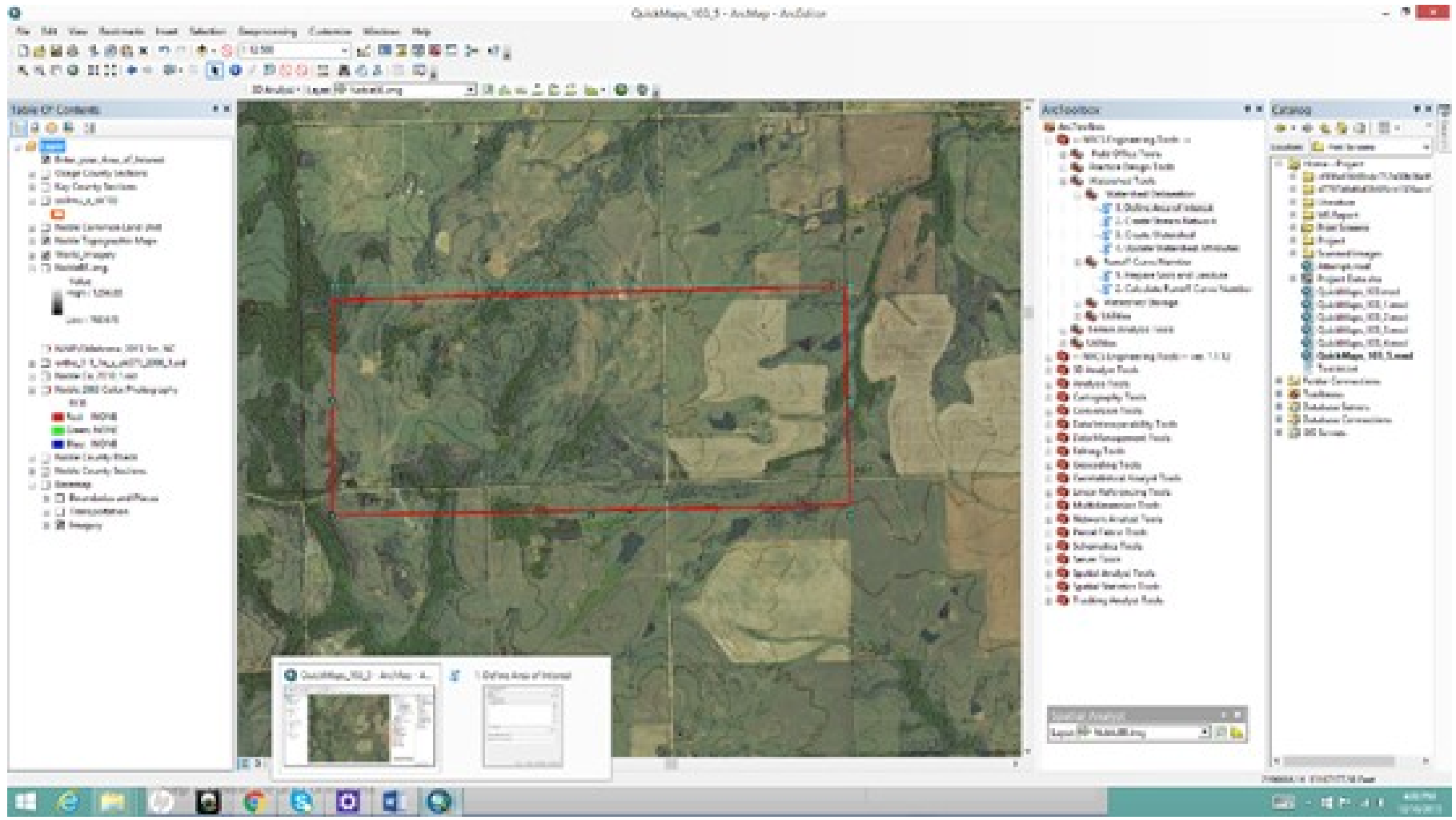

Figure A6. Access DIA window again 
- Now with DIA window open again under "Enter your Area of Interest" there is now a number 1 . An ID can be assigned to this number but for this project since there is only one area of interest the ID has been left blank (Figure A7).

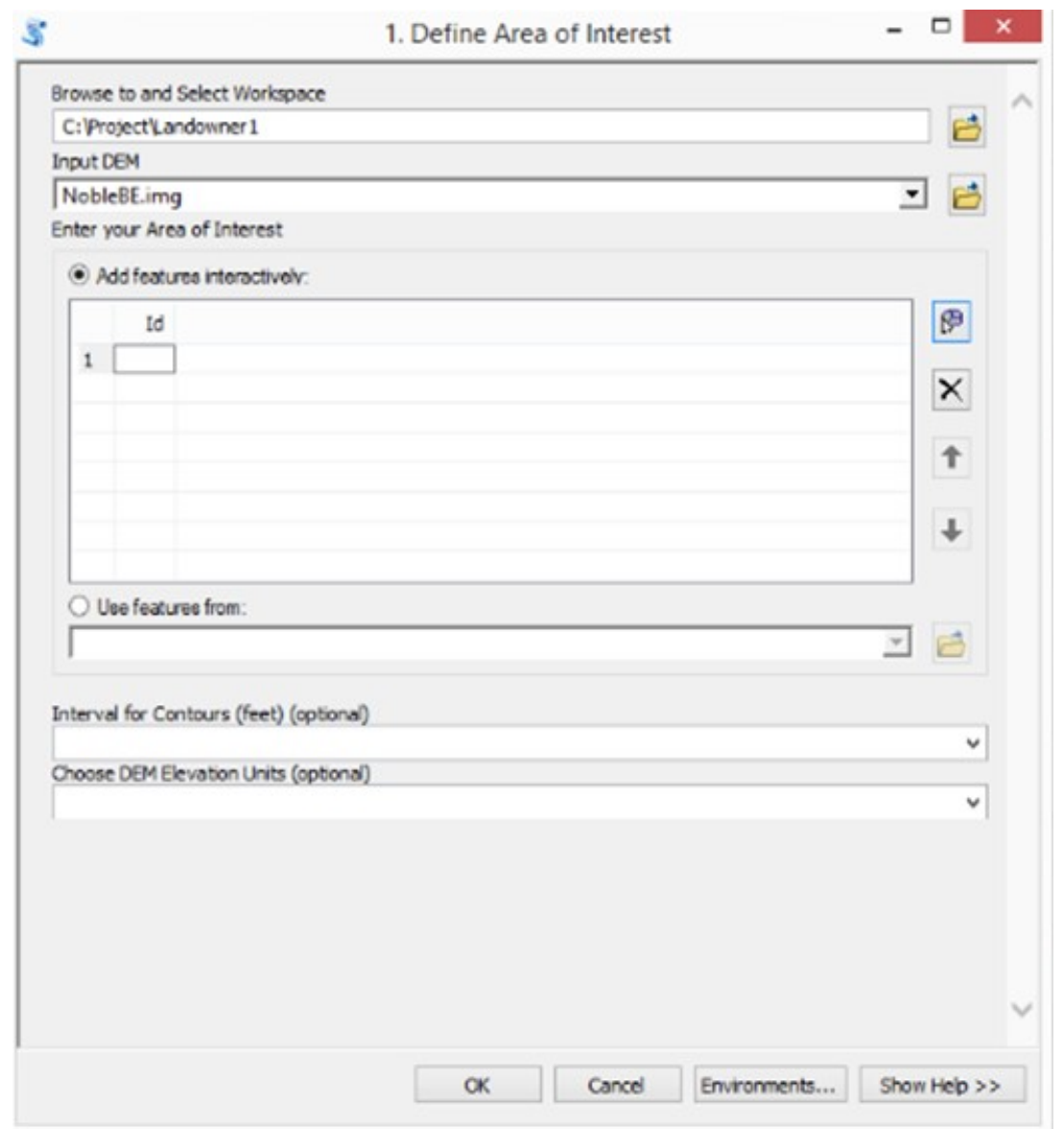

Figure A7. Area of Interest ID left blank.

- Lastly select the appropriate value for the "Interval for Contours" and the appropriate units for the "DEM Elevation Units" at the bottm. For this project the topographic maps had intervals of 10 and the units used were in feet.

- Select ok and let the tool run. Once it has done so successfully the read out should be similar to Figure A8. 


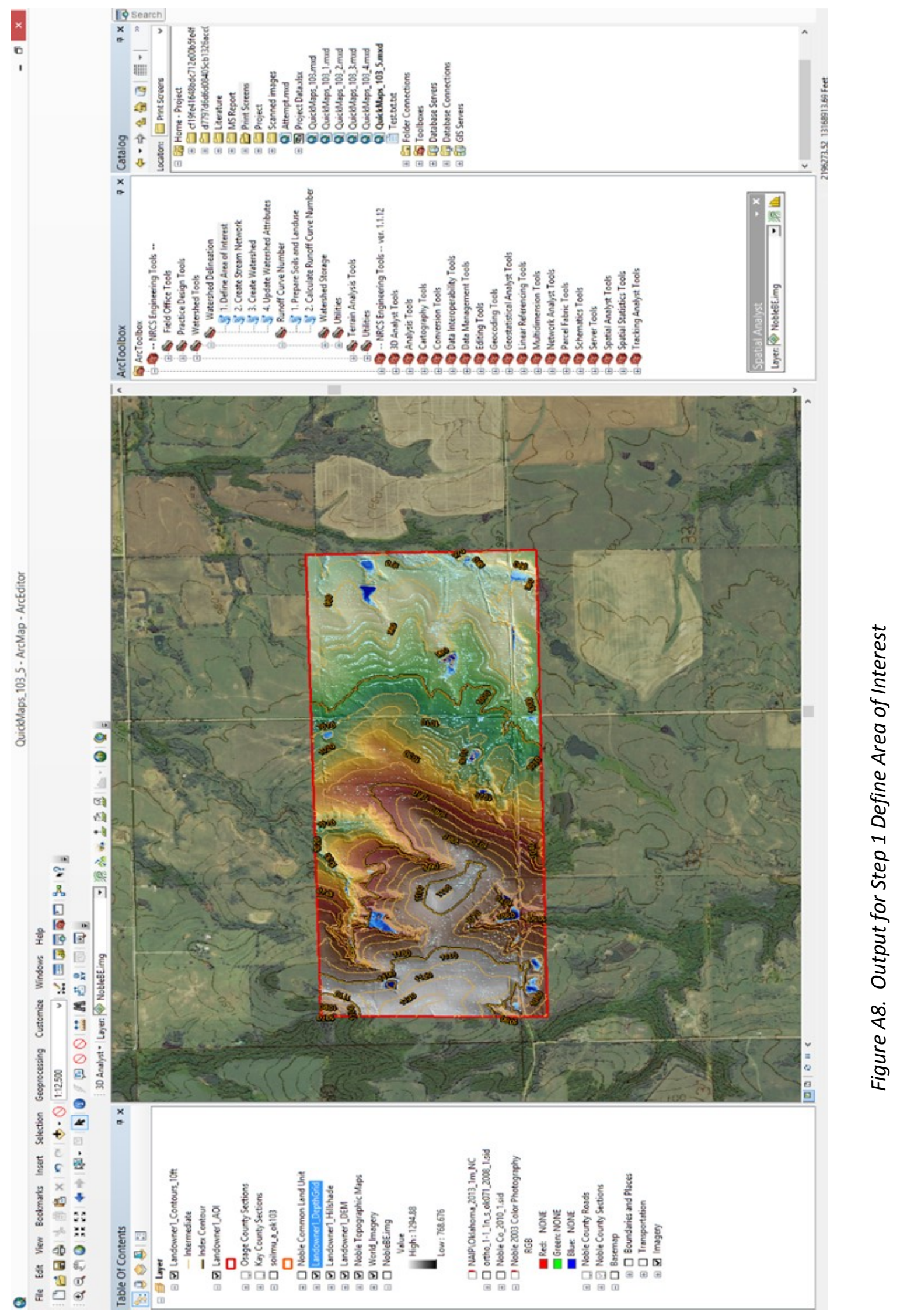


Step 2: Create Stream Network,

- In ArcToolbox select NRCS Engineering Tools. Then select watershed tools. Under watershed delineation double click "create stream network" to open CSN (Create Stream Network) window (Figure A9).

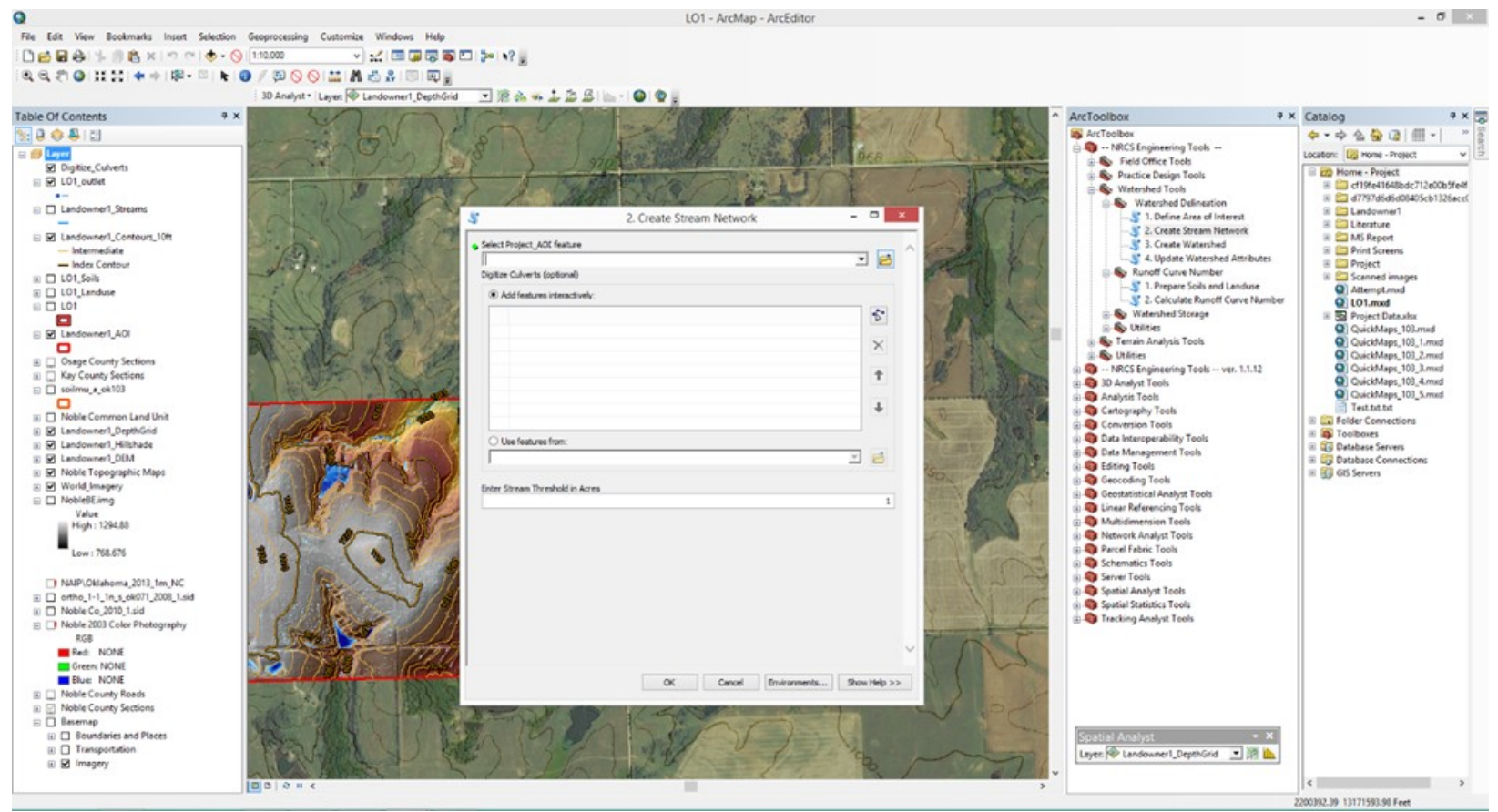

Figure A9. Create stream network window

- After opening the CSN window select the black downward facing arrow next to the folder to navigate through the layers to select the area of interest layer just created in previous step 1. For this project the layer was named Landowner1_AOI.

- Since there are no culverts associated with this structure there is not any additional data to add. Also the stream threshold in acres can remain at 1.

- Select ok

- Let the tool run. Once it has done so successfully the read out should be similar to Figure A10. 


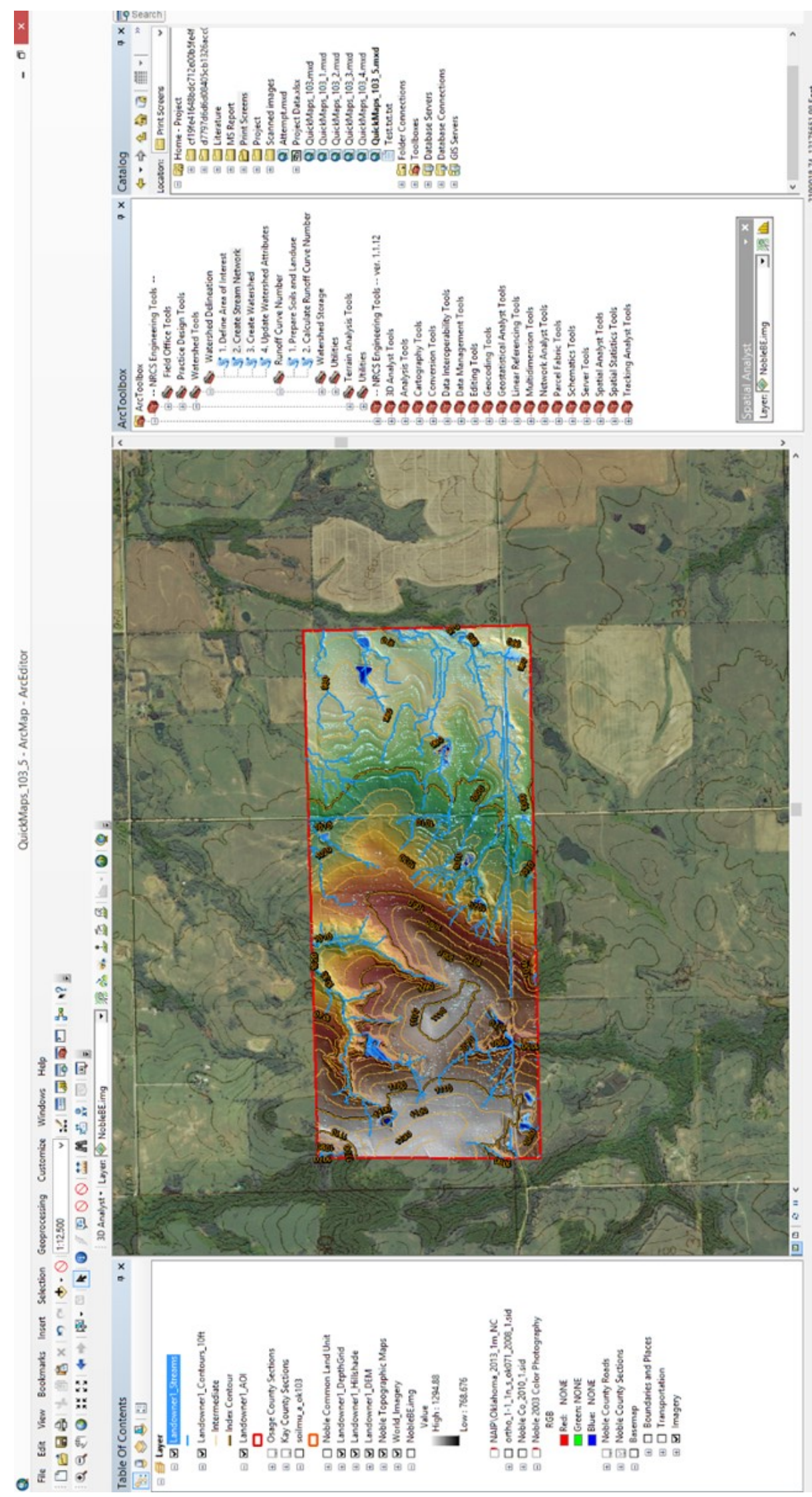

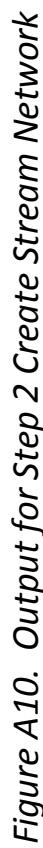


Step 3: Create Watershed,

- Now that the stream network has been created the watershed can now be created.

Turn off the depth grid layer, hillshade layer, and DEM layer (Figure A11- A13).

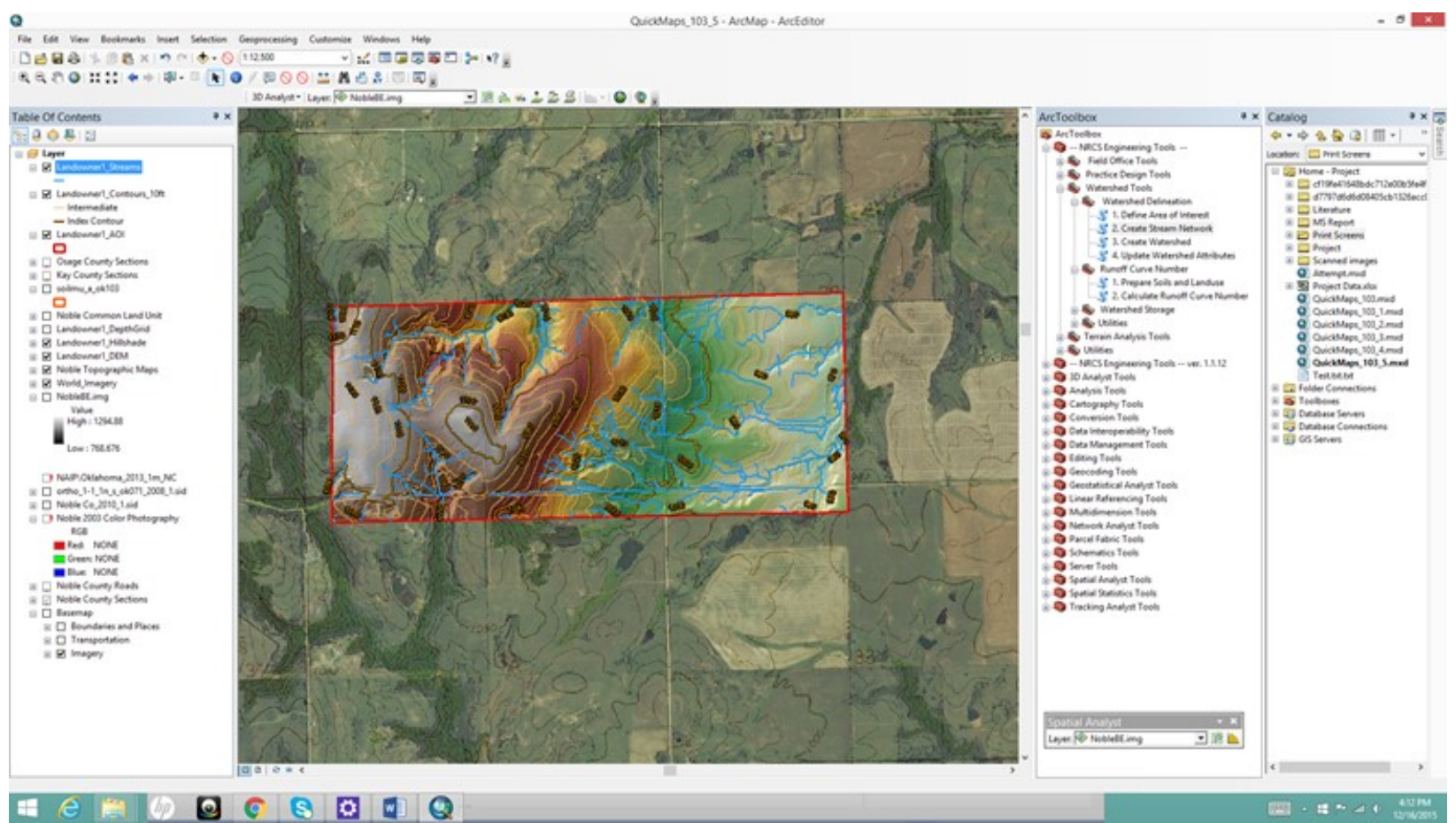

Figure A11. Depth gird layer turned off

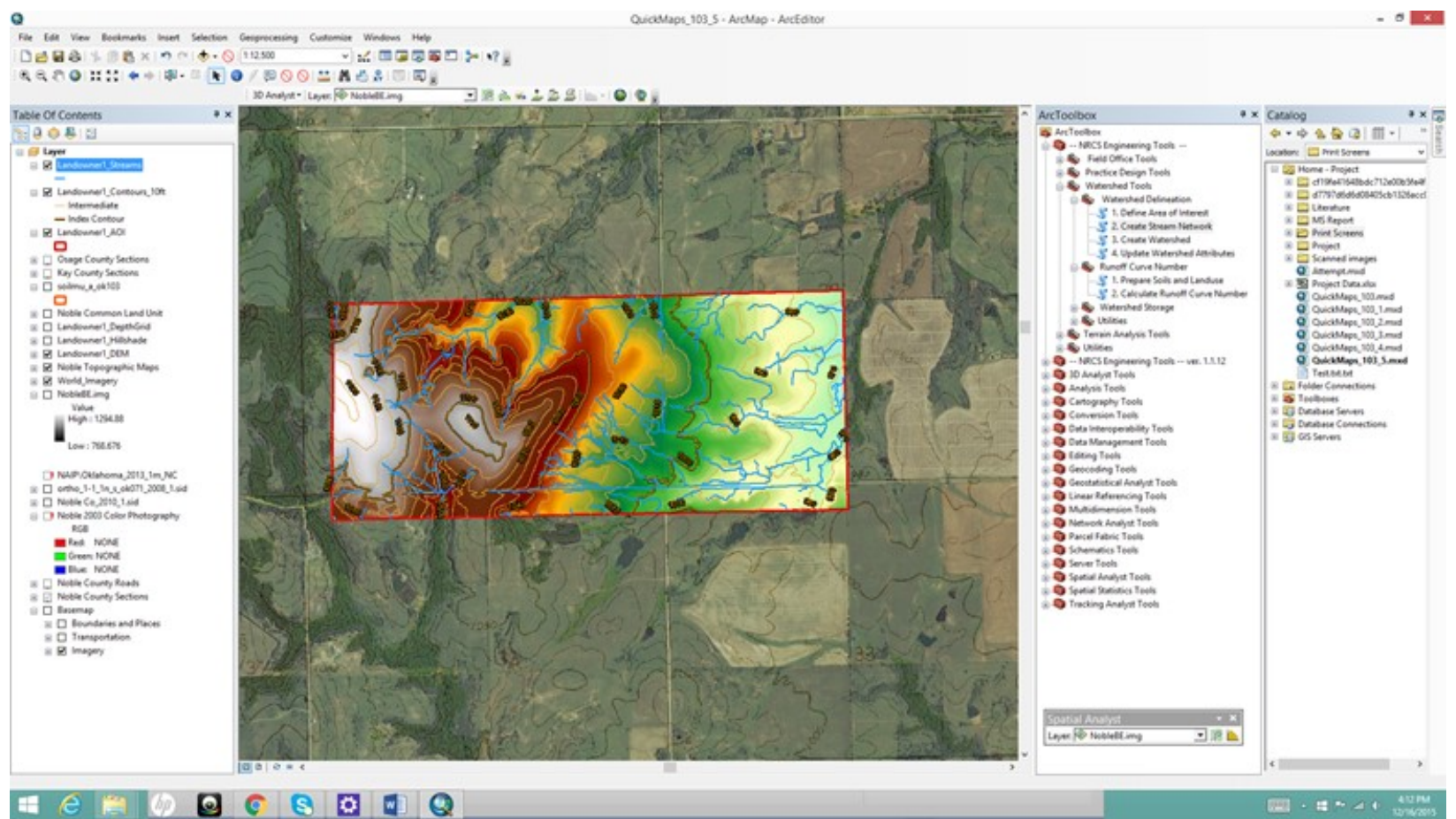


Figure A12. Hillshade layer turned off

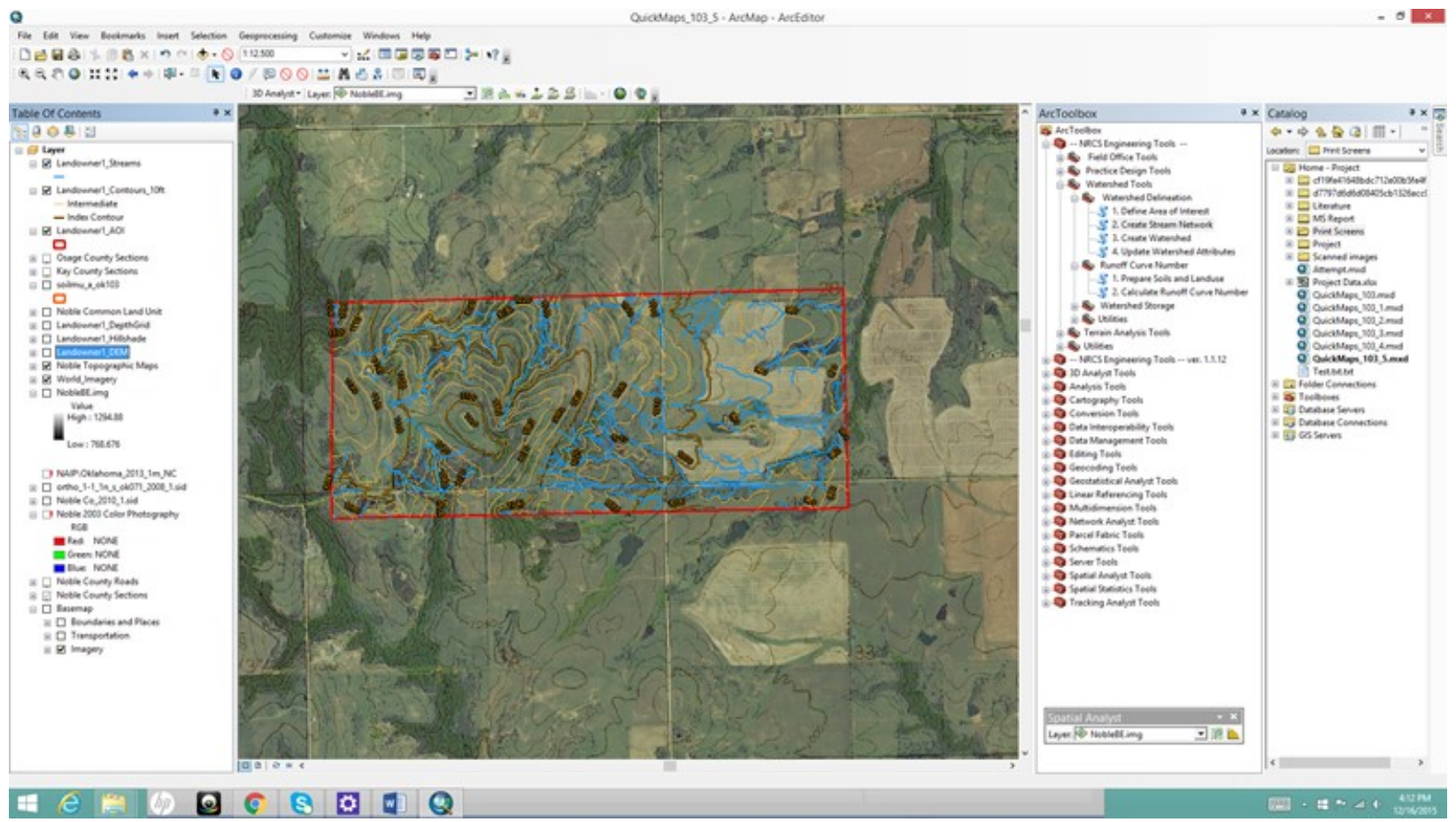

Figure A13. DEM layer turned off

- Now zoom into the structure of interest to have a better view of what the generated streams are doing in that structure (Figure A14)

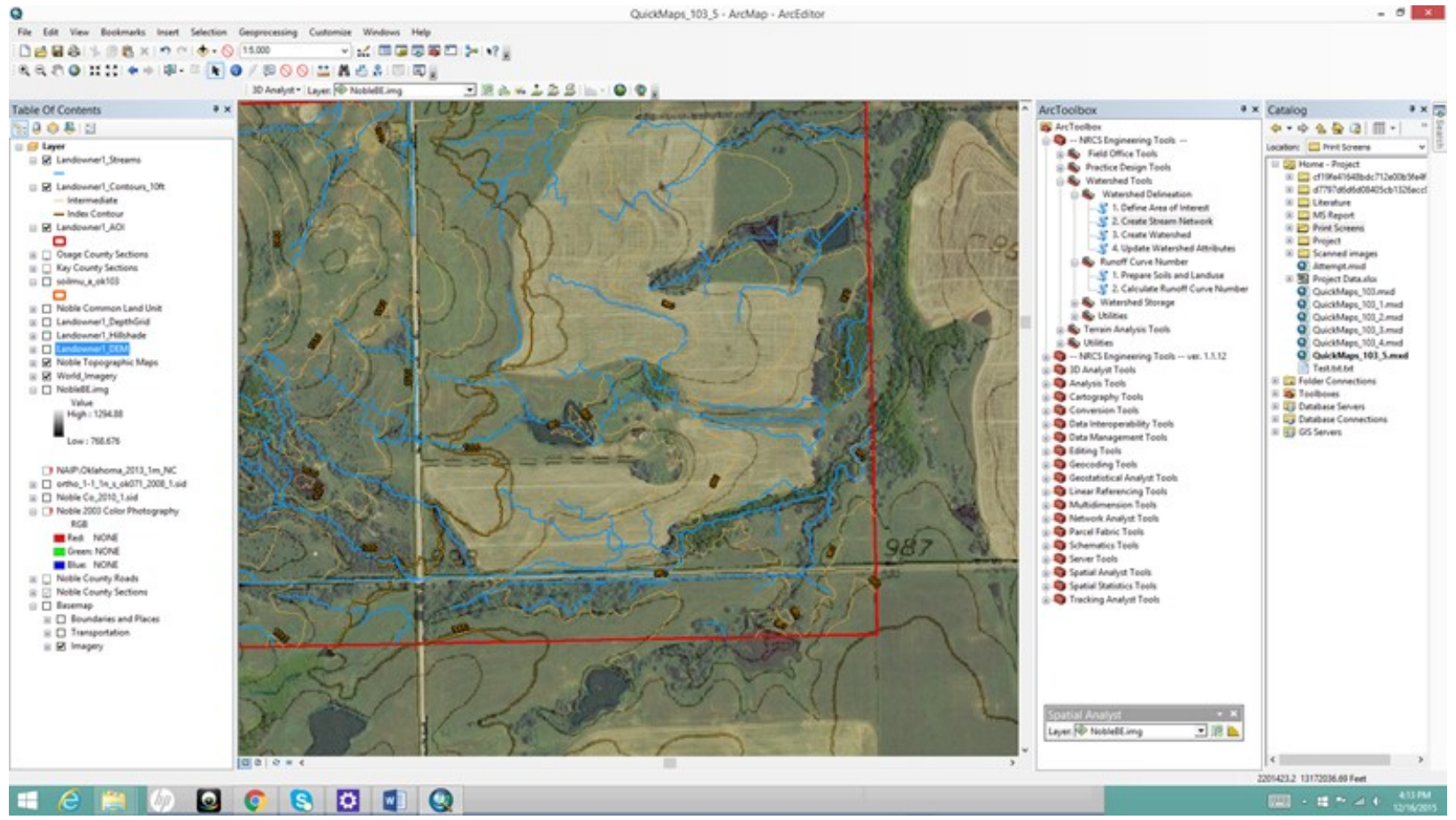

Figure A14. Closer view of stream networks and grassed waterway of interest 
- In ArcToolbox select NRCS Engineering Tools. Then select watershed tools. Under watershed delineation double click "create watershed" to open CW (Create Watershed) window.

- After opening the $\mathrm{CW}$ window select the black downward facing arrow next to the folder to navigate through the layers to select the stream layer just created in previous step 2. For this project the layer was named Landowner1_Streams.

- Next select the add feature button to be able to draw the outlet of the watershed. Be sure to minimize the window before doing so to allow for more workspace (Figure A15-A16).

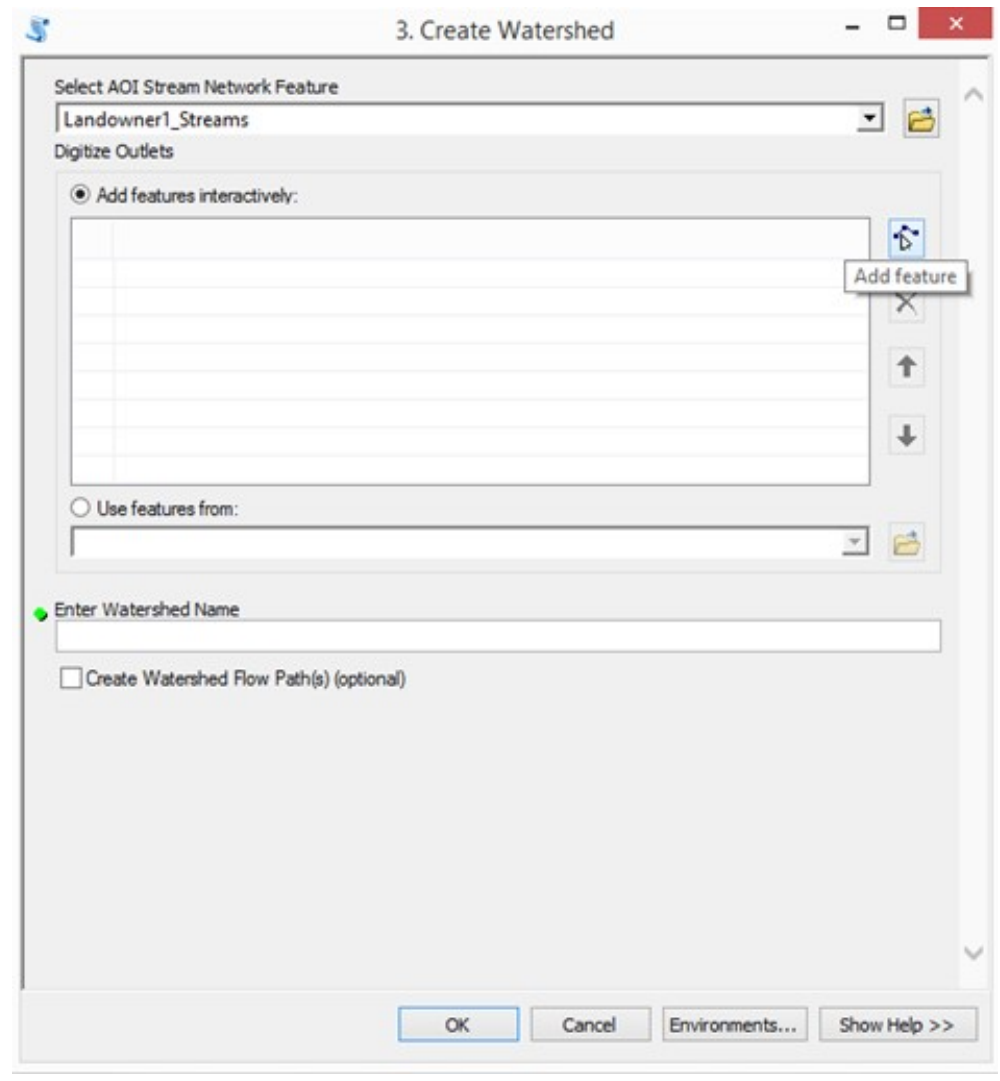

Figure A15. Select the add feature button to draw outlet of watershed 

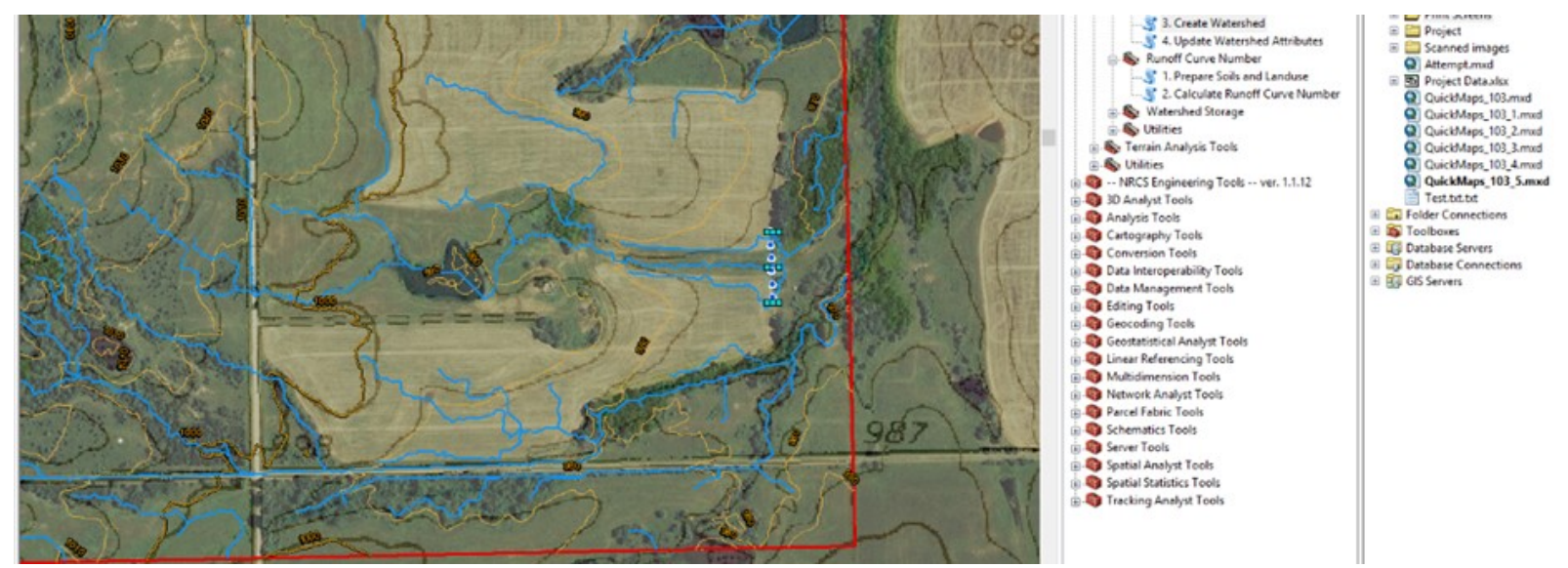

Figure A16. Drawing th outlet for the watershed

- Hover over the ArcMap icon (the earth with magnifying glass) in the windows bar running along the bottom of the screen below to access CW window again.

- Now with CW window open again under "Add features interactively" there is now a number 1 representing the single outlet for a single watershed (Figure A17).

- Lastly where it says "Enter Watershed Name" type in an appropriate name for the watershed that is going to be created. For this project this watershed is named LO1 (Figure A17). Select ok when finish naming

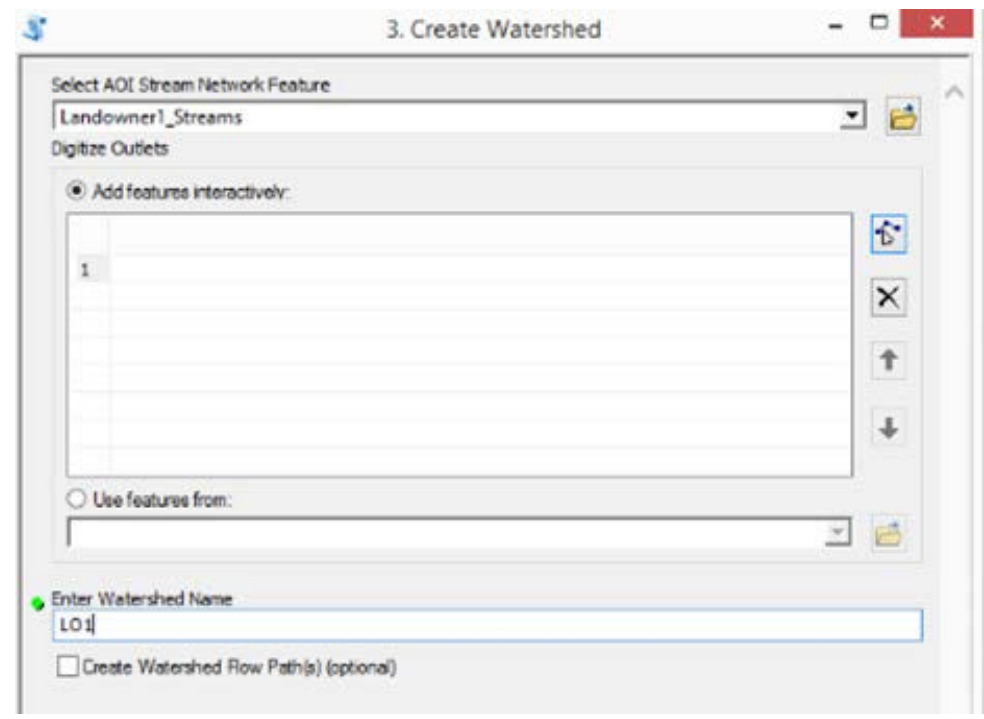

Figure A17. Outlet identification and watershed name

- Let the tool run. Once it has done so successfully the read out should be similar to the following two images. 


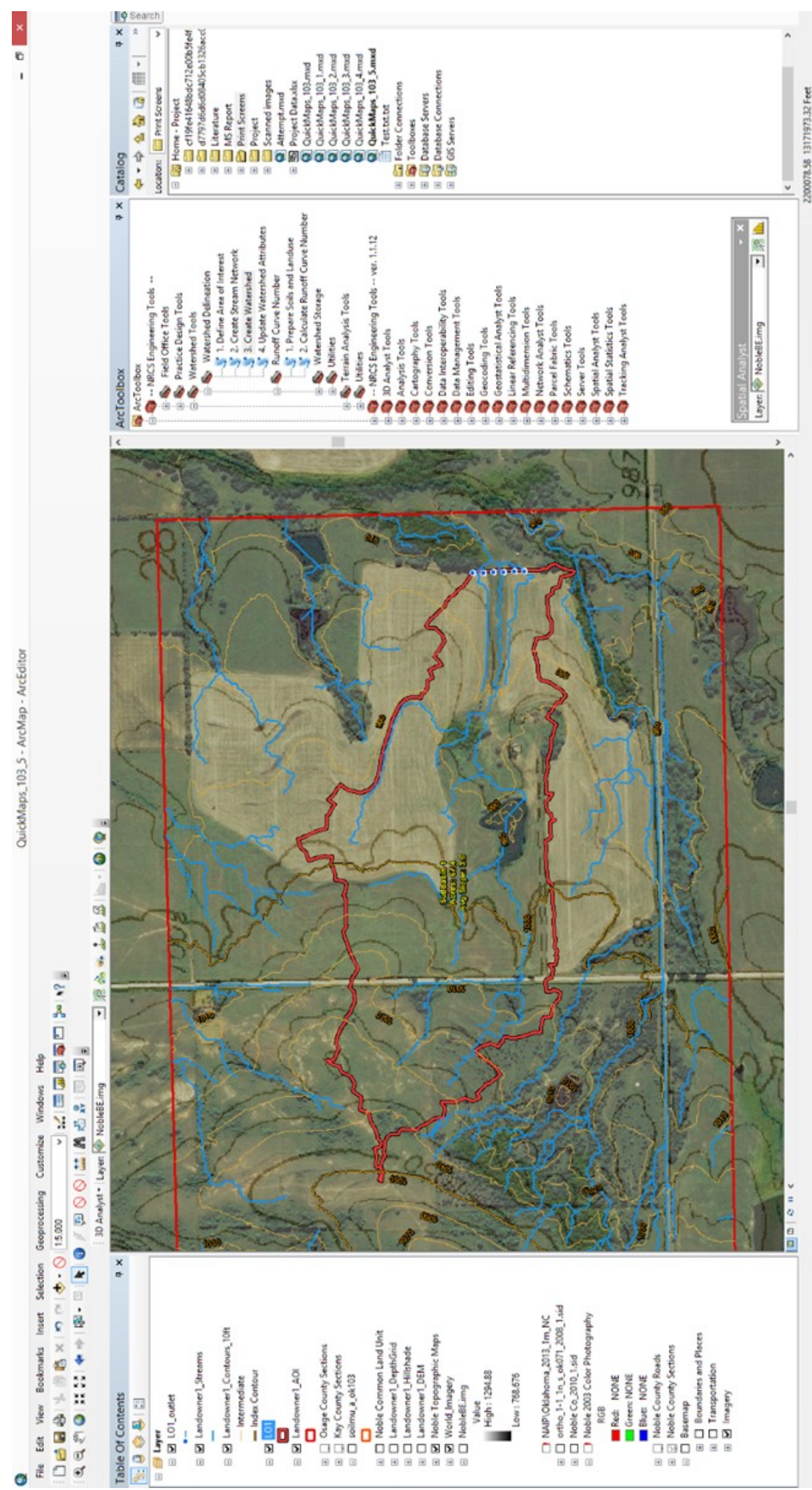

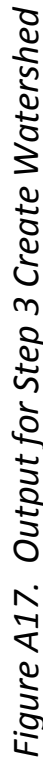


Prepare Soils and Landuse

- Next in ArcToolbbox use the Runoff Curve Number "Prepare Soils and Landuse" to determine the acres of different soils in the watershed to be used in the calculation of the curve number using the EFT tool.

- In ArcToolbox select NRCS Engineering Tools. Then select Runoff Curve Number. Double click Step 1. Prepare Soils and Landuse (PSL)

- After opening the PSL window select the black downward facing arrow next to the first folder to navigate through the layers to select the input watershed layer just created in previous step 3. For this project the layer was named LO1 (Figure A18).

- Select the next black downward facing arrow next to the second folder to navigate through the layers to select the input soils layer. For this project the soil layer is soilmu_a_ok103 (Figure A18).

- Select the next black downward facing arrow below the second folder to navigate through the layers to select the hydrologic field from soils layer. For this project the desired layer is MUSYM (Figure A18).

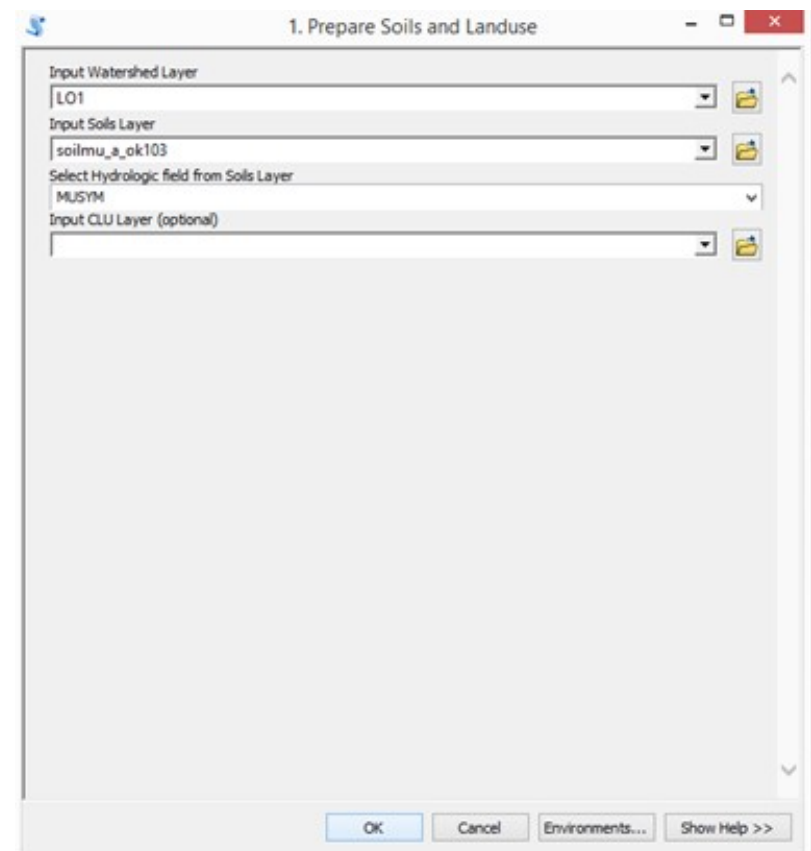

Figure A18. Input watershed layer name, Input soils layer, Hydrologic field 
- Select ok and let the tool run. Once it has done so successfully the read out should be similar to Figure A19

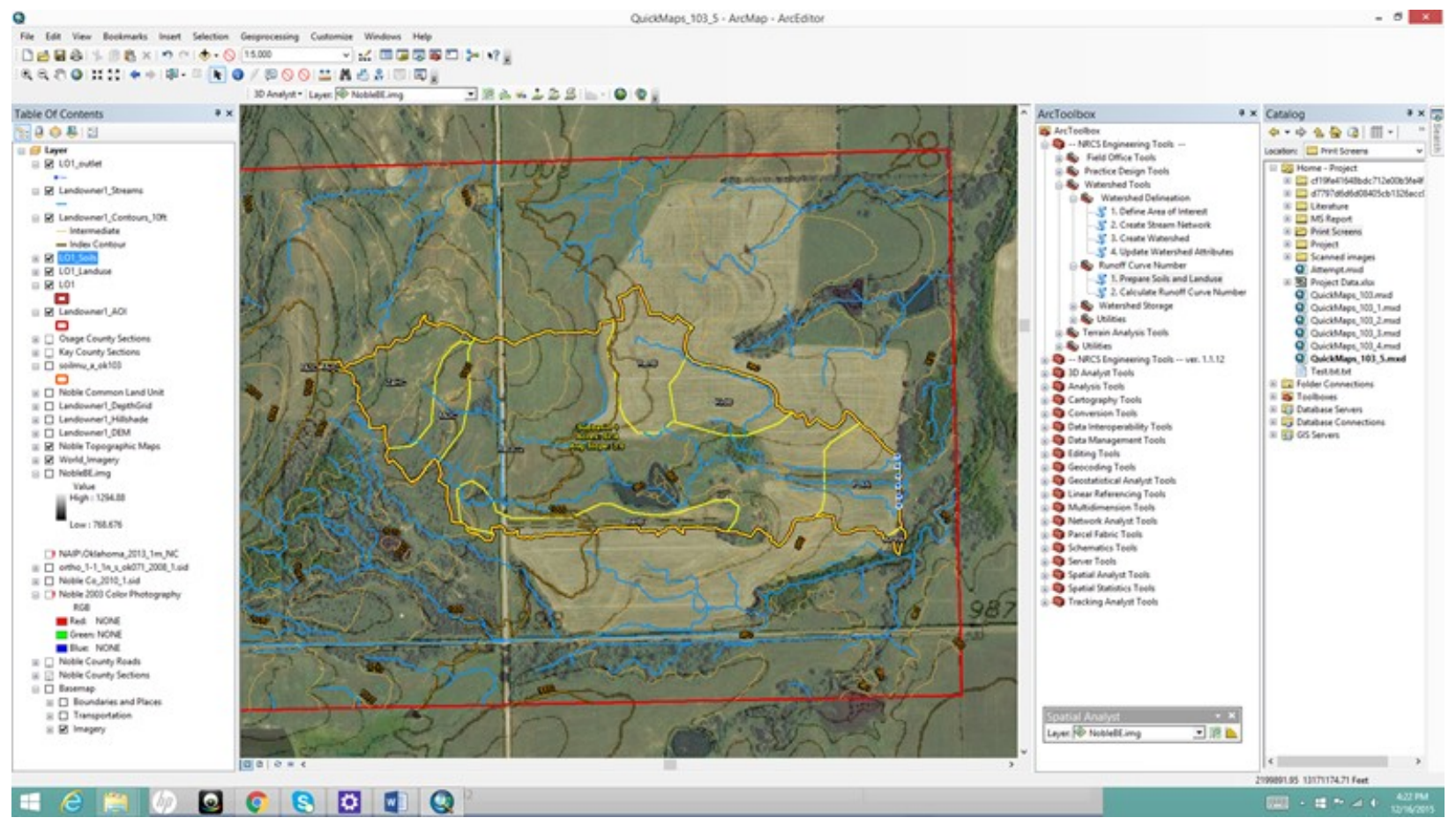

Figure A19. Output for Prepare Soils and Landuse

- Now in table of contents right click the new LO1_Soils layer and select "open attribute table" (Figure A20).

Q

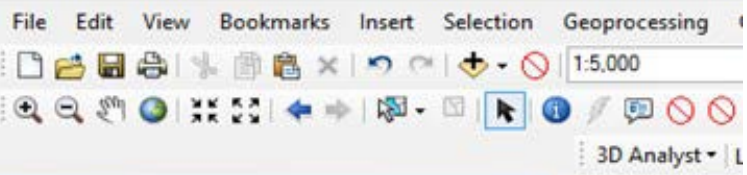

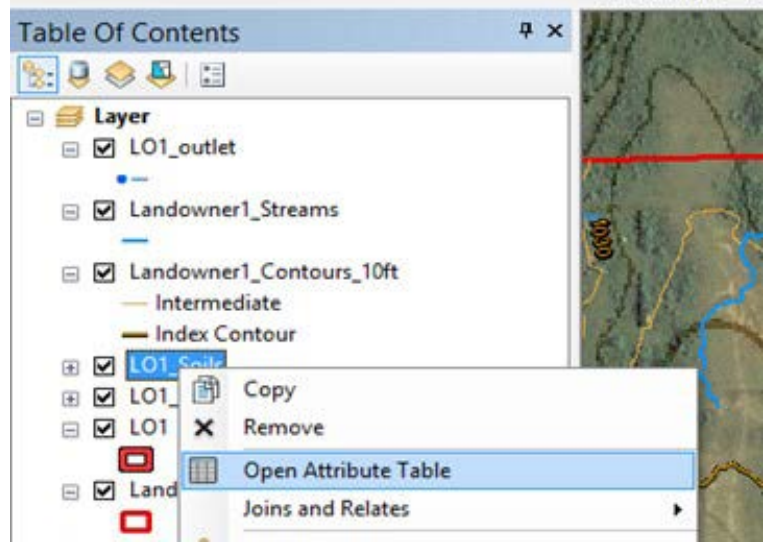

Figure A20. Open attribute table of newly created LO1_Soils Layer 
- Select the black arrow of the Table Options tab and select add field (Figure A21)

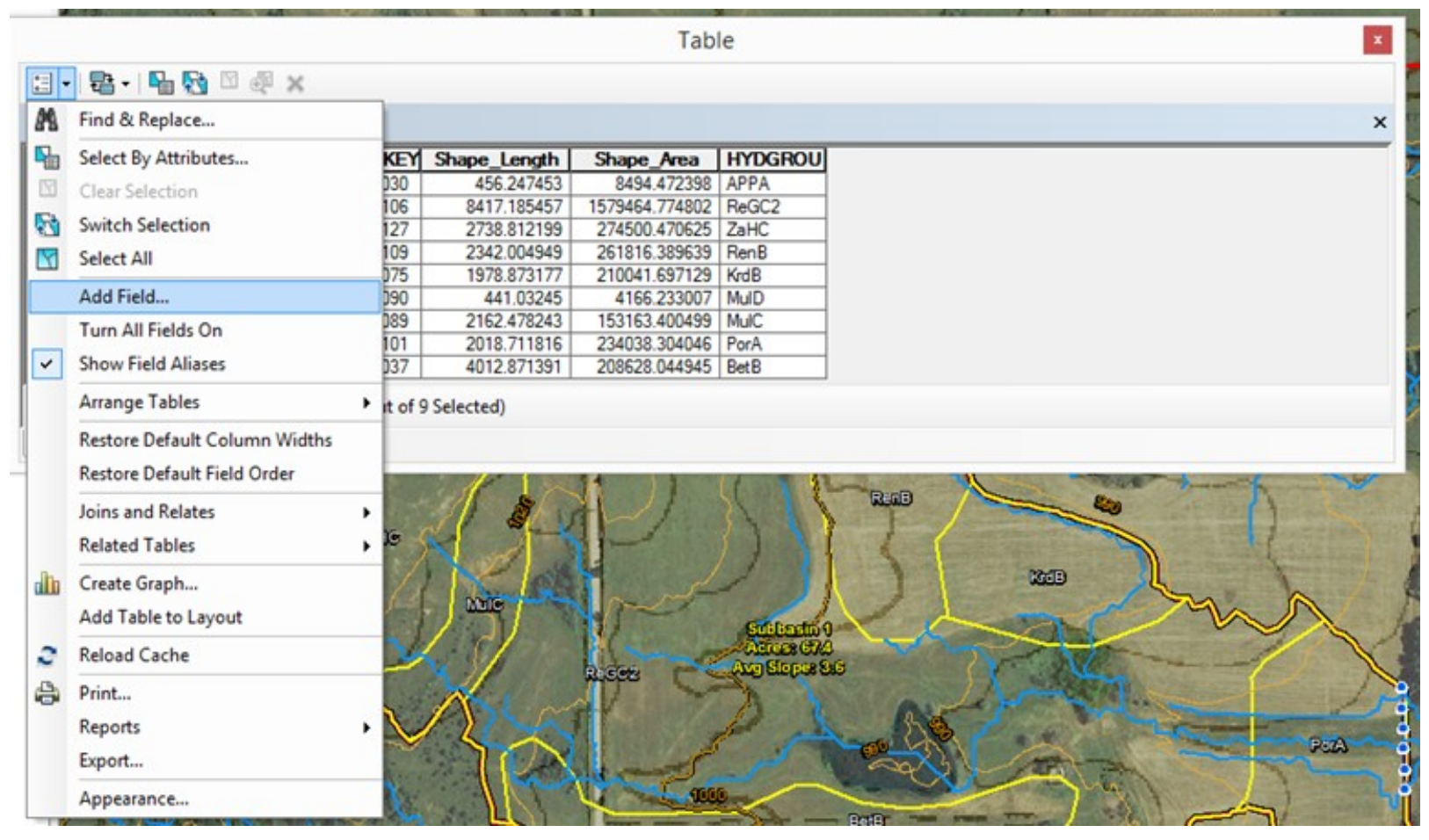

Figure A21. Select Table Options to select Add Field

- Type "Area_Acres" for the name in the Add Field window and change type to float (Figure A22). Leave everything else as is. Select ok.

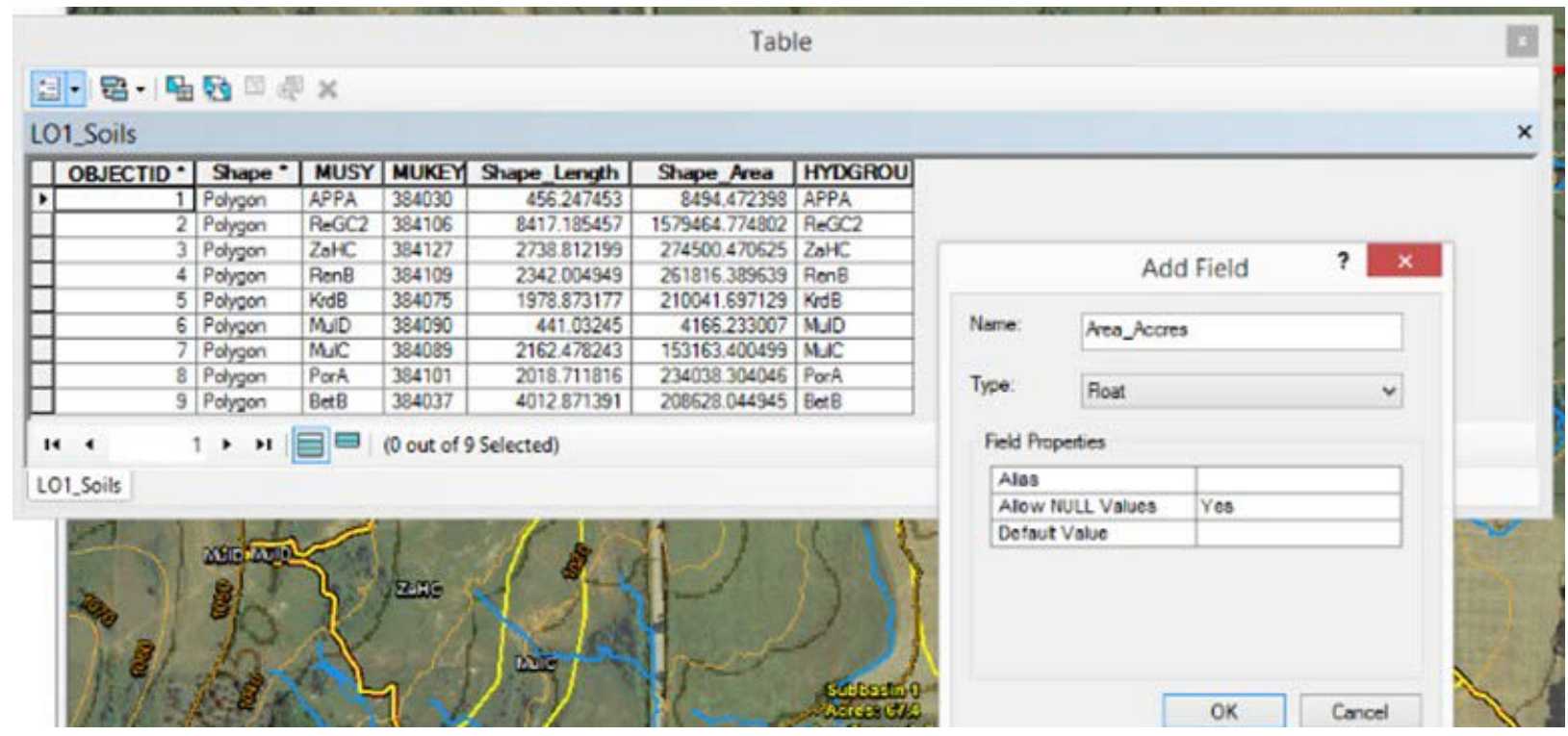

Figure A22. Add field window name and type 
- A new field has been successfully created (Figure A23).

\begin{tabular}{|c|c|c|c|c|c|c|c|c|c|}
\hline & \multicolumn{8}{|c|}{ Table } & \multirow[t]{2}{*}{$x$} \\
\hline \multicolumn{9}{|c|}{ 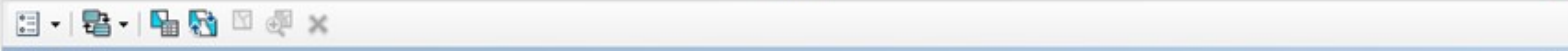 } & \\
\hline \multicolumn{9}{|c|}{ LO1_Soils } & $x$ \\
\hline 口 & OBNECTID * & Shape * & MUSY & MUKEY & Shape_Length & Shape_Area & HYDGROU & Area_Accres & \\
\hline \multirow{9}{*}{5} & 1 & Polygon & APPA & 384030 & 456.247453 & 8494.472398 & APPA & 〈Null> & \\
\hline & 2 & Polygon & ReGC2 & 384106 & 8417.185457 & 1579464.774802 & ReGC2 & 〈Null $\rangle$ & \\
\hline & 3 & Polygon & $\mathrm{ZaHC}$ & 384127 & 2738.812199 & 274500.470625 & $\mathrm{ZaHC}$ & 〈Null> & \\
\hline & 4 & Polygon & $\operatorname{Ren} B$ & 384109 & 2342.004949 & 261816.389639 & Ren B & 〈Null > & \\
\hline & 5 & Polygon & KrdB & 384075 & 1978.873177 & 210041.697129 & $\mathrm{KrdB}$ & 〈Null $\rangle$ & \\
\hline & 6 & Polygon & MulD & 384090 & 441.03245 & 4166.233007 & Muld & 〈Null> & \\
\hline & 7 & Polygon & MulC & 384089 & 2162.478243 & 153163.400499 & MulC & 〈Null $\rangle$ & \\
\hline & 8 & Polygon & PorA & 384101 & 2018.711816 & 234038.304046 & PorA & 〈Null> & \\
\hline & & Polygon & BetB & 384037 & 4012.871391 & 208628.044945 & BetB & 〈Null> & \\
\hline 1 & 4 & $\mid n$ & 冒目| & ( 0 out of 9 & 9 Selected) & & & & \\
\hline & 1.Soils & & & & & & & & \\
\hline
\end{tabular}

Figure A23. New field Area_Acres created

- $\quad$ Right click the new field Area_Acres. Select calculate geometry (Figure A24)

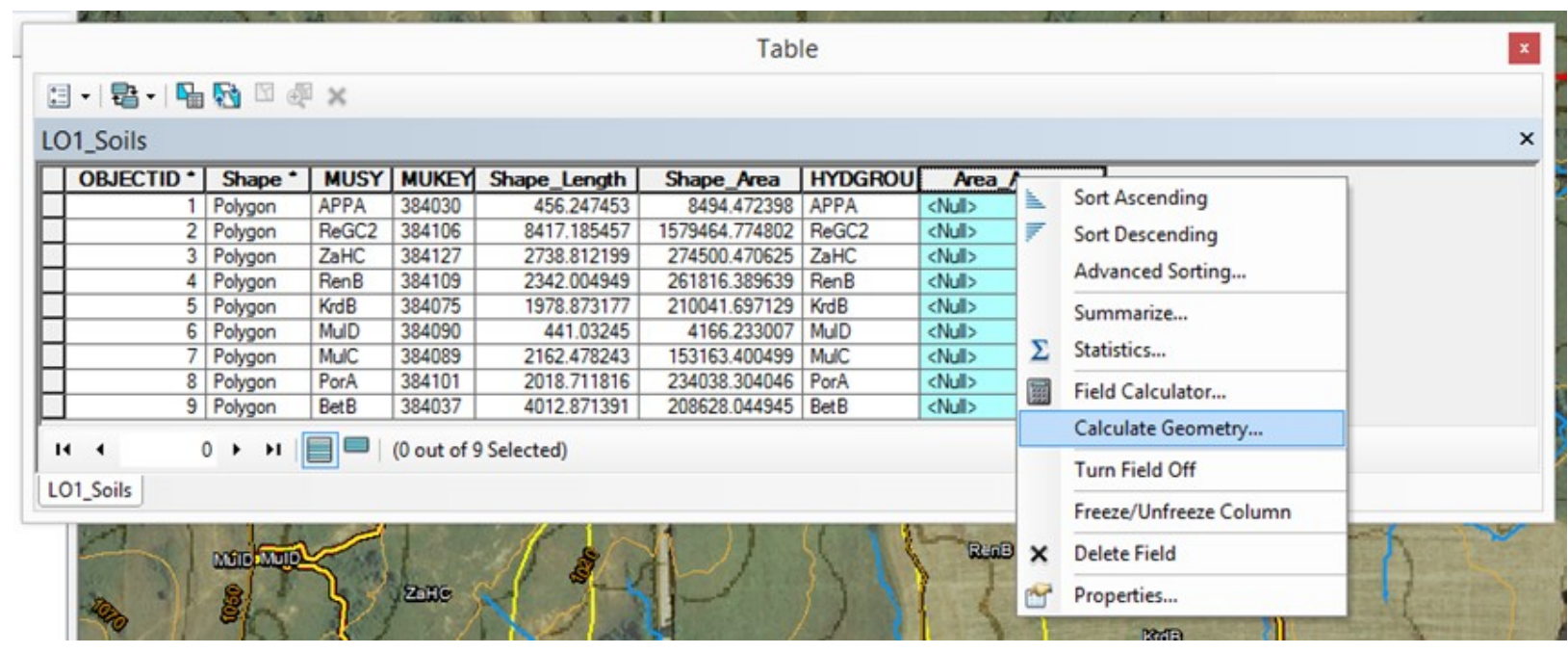

Figure A24. Calculate geometry from right clicking on the newly created field

- When the window prompt appears saying "you are about to do a calculate outside of an edit session...." select yes

- Next the Calculate Geometry window opens. Leave property as area and use coordinate system of the data source as selected. Set units to Acres US. Select ok. (Figure A25) 


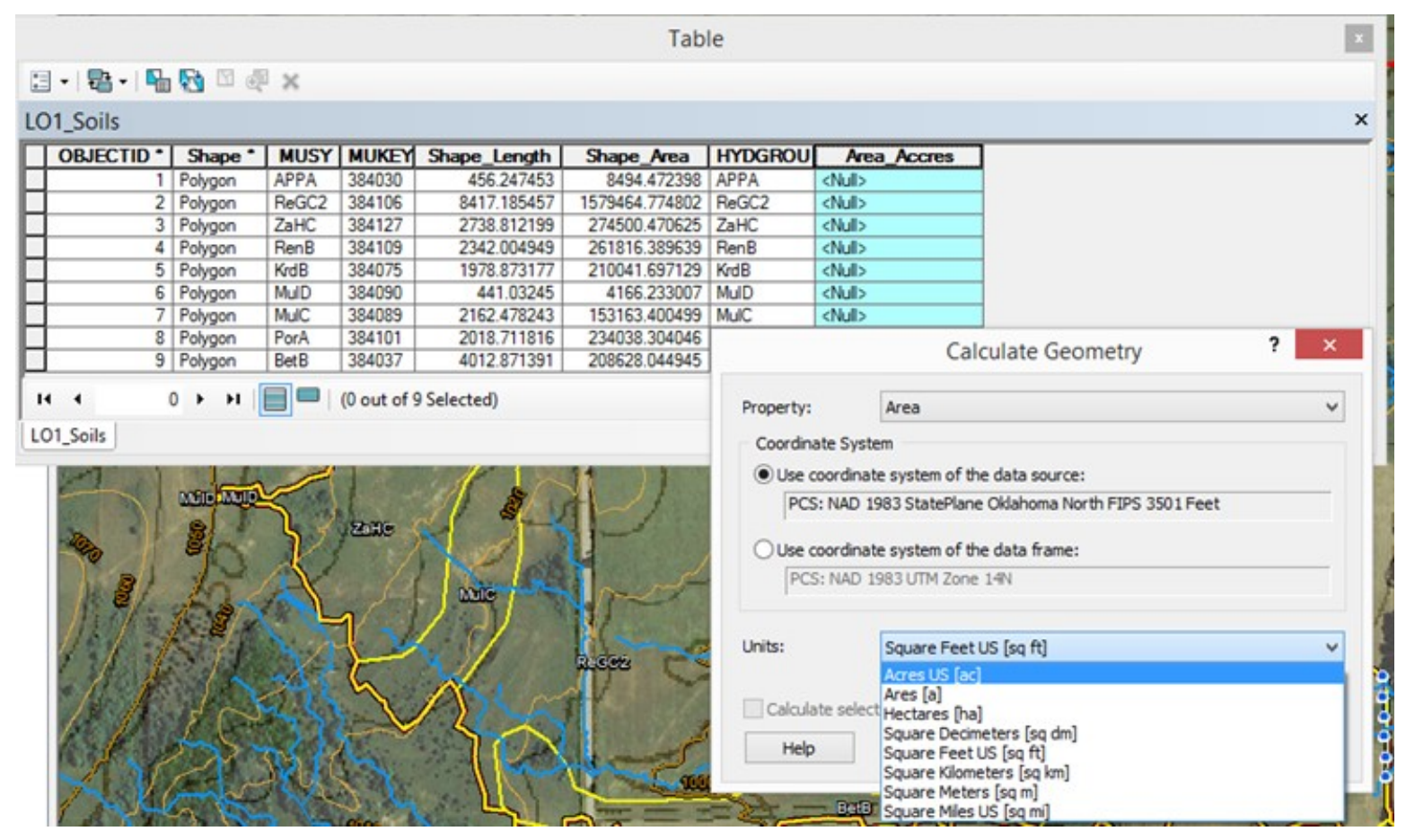

Figure A25.Calcualte Geometery property, coordinate system, and units

- The acres of each soil type in the watershed are now known and available for use for Runoff Curve Calculation using EFT tool. 